\title{
Patterns of medicinal cannabis use, strain analysis, and substitution effect among patients with migraine, headache, arthritis, and chronic pain in a medicinal cannabis cohort
}

Eric P. Baron ${ }^{*}$, Philippe Lucas ${ }^{2,3,4}$, Joshua Eades ${ }^{2}$ and Olivia Hogue ${ }^{5}$

\begin{abstract}
Background: Medicinal cannabis registries typically report pain as the most common reason for use. It would be clinically useful to identify patterns of cannabis treatment in migraine and headache, as compared to arthritis and chronic pain, and to analyze preferred cannabis strains, biochemical profiles, and prescription medication substitutions with cannabis.

Methods: Via electronic survey in medicinal cannabis patients with headache, arthritis, and chronic pain, demographics and patterns of cannabis use including methods, frequency, quantity, preferred strains, cannabinoid and terpene profiles, and prescription substitutions were recorded. Cannabis use for migraine among headache patients was assessed via the ID Migraine ${ }^{\mathrm{TM}}$ questionnaire, a validated screen used to predict the probability of migraine.

Results: Of 2032 patients, 21 illnesses were treated with cannabis. Pain syndromes accounted for $42.4 \%(n=861)$ overall; chronic pain 29.4\% ( $n=598 ;)$, arthritis 9.3\% $(n=188)$, and headache 3.7\% $(n=75 ;)$. Across all 21 illnesses, headache was a symptom treated with cannabis in $24.9 \%(n=505)$. These patients were given the ID Migrain ${ }^{\mathrm{TM}}$ questionnaire, with 68\% $(n=343)$ giving 3 "Yes" responses, 20\% $(n=102)$ giving 2 "Yes" responses $(97 \%$ and 93\% probability of migraine, respectively). Therefore, $88 \%(n=445)$ of headache patients were treating probable migraine with cannabis. Hybrid strains were most preferred across all pain subtypes, with "OG Shark" the most preferred strain in the ID Migraine ${ }^{\mathrm{TM}}$ and headache groups. Many pain patients substituted prescription medications with cannabis (41.2-59.5\%), most commonly opiates/opioids (40.5-72.8\%). Prescription substitution in headache patients included opiates/opioids (43.4\%), anti-depressant/anti-anxiety (39\%), NSAIDs (21\%), triptans (8.1\%), anticonvulsants (7.7\%), muscle relaxers (7\%), ergots (0.4\%).

(Continued on next page)
\end{abstract}

\footnotetext{
* Correspondence: barone2@ccf.org

${ }^{1}$ Center for Neurological Restoration - Headache and Chronic Pain Medicine,

Department of Neurology, Cleveland Clinic Neurological Institute, 10524

Euclid Avenue, C21, Cleveland, OH 44195, USA

Full list of author information is available at the end of the article
} 
(Continued from previous page)

Conclusions: Chronic pain was the most common reason for cannabis use, consistent with most registries. The majority of headache patients treating with cannabis were positive for migraine. Hybrid strains were preferred in ID Migraine $^{\text {TM}}$, headache, and most pain groups, with "OG Shark", a high THC ( $\Delta$ 9-tetrahydrocannabinol)/THCA (tetrahydrocannabinolic acid), low CBD (cannabidiol)/CBDA (cannabidiolic acid), strain with predominant terpenes $\beta$ caryophyllene and $\beta$-myrcene, most preferred in the headache and ID Migraine ${ }^{\mathrm{TM}}$ groups. This could reflect the potent analgesic, anti-inflammatory, and anti-emetic properties of THC, with anti-inflammatory and analgesic properties of $\beta$-caryophyllene and $\beta$-myrcene. Opiates/opioids were most commonly substituted with cannabis. Prospective studies are needed, but results may provide early insight into optimizing crossbred cannabis strains, synergistic biochemical profiles, dosing, and patterns of use in the treatment of headache, migraine, and chronic pain syndromes.

Keywords: Cannabis, Cannabinoids, Marijuana, CBD, Cannabidiol, THC, $\Delta^{9}$-tetrahydrocannabinol, Migraine, Headache, Terpenes, Arthritis, Pain

\section{Background}

The legal use of medicinal cannabis continues to increase globally, including the United States. At the time of this writing, there are currently 29 states which have legalized medicinal cannabis, 9 states and Washington DC which have legalized both medicinal and recreational cannabis use, and 18 states which have legalized cannabidiol (CBD)-only bills.

The use of medicinal cannabis for a multitude of health maladies, particularly chronic pain, has been well described through ancient, historical, and current times, and well supported through the medical literature [1-28]. In 2017, The National Academies of Sciences, Engineering, and Medicine published a statement that the use of cannabis for the treatment of pain is supported by wellcontrolled clinical trials and that there is substantial evidence that cannabis is an effective treatment for chronic pain in adults [24]. In 2014, the Canadian Pain Society revised their consensus statement to recommend cannabinoids as a third-level therapy for chronic neuropathic pain given the evidence of cannabinoid efficacy in the treatment of pain with a combined number needed to treat (NNT) of 3.4 [25]. Most medicinal cannabis registries report that chronic pain is the most common indication for use [29-39]. However, most of these registries do not further differentiate chronic pain into different pain subsets.

Supporting evidence also exists for cannabis/cannabinoids in the treatment of migraine and/or chronic migraine $[1,40-56]$, cluster headache [56-59], chronic headaches $[13,44,60,61]$, medication overuse headache [62], idiopathic intracranial hypertension [63], and multiple sclerosis associated trigeminal neuralgia [64]. Publications detailing this headache, migraine, and facial pain literature, as well as described mechanisms of pain relief with cannabis and cannabinoids are available and should be reviewed, but are beyond the scope of this paper $[1,2,28,51,65]$. At the time of this writing, the limited supporting headache literature consists of one retrospective analysis, numerous case series, case studies, and case reports, clinical/anecdotal reports, and surveys. There are no placebo-controlled studies of cannabis for headache disorders, although a multicenter, double-blind, placebo-controlled study evaluating efficacy and safety of a synthetic $\Delta^{9}$-tetrahydrocannabinol (THC), Dronabinol, in a metered dose inhaler for the treatment of migraine with and without aura has been completed, but results not available [66]. There are only two prospective trials containing a control group evaluating the use of cannabinoids in the treatment of headache disorders, specifically chronic migraine, cluster headache, and medication overuse headache [56, 62].

The first of these two prospective trials was a randomized, double-blind, active-controlled crossover trial with treatment refractory medication overuse headache $(\mathrm{MOH})$ with daily analgesic intake for at least 5 years and several failed detoxification attempts. Patients completed a course of either Ibuprofen $400 \mathrm{mg}$ or Nabilone $0.5 \mathrm{mg}$ daily for 8 weeks, had a 1 week washout, then a second 8 weeks of the other medication. Results showed that Nabilone $0.5 \mathrm{mg}$ daily, a synthetic cannabinoid, was superior in reducing daily analgesic intake, pain intensity, level of medication dependence, and improved quality of life in these patients [62].

The second prospective trial evaluated the use of cannabinoids as both a prophylaxis and acute treatment for both chronic migraine and chronic cluster headache [56]. Patients were given one of two compounds containing $19 \% \mathrm{THC}$ or a combination of $0.4 \% \mathrm{THC}+9 \%$ CBD. In phase 1 , dose finding observations to determine effective dosing was performed with a group of 48 chronic migraineurs. It was found that doses less than $100 \mathrm{mg}$ produced no benefit, while an oral dose of $200 \mathrm{mg}$ administered during a migraine attack decreased acute pain intensity by $55 \%$, which was the dose used in phase 2. In phase 2, chronic migraine patients were assigned to 3 months prophylaxis treatment with either 
$25 \mathrm{mg}$ per day of Amitriptyline or THC + CBD $200 \mathrm{mg}$ per day. Chronic cluster headache patients were assigned to 1 month prophylaxis treatment with either Verapamil $480 \mathrm{mg}$ per day or $\mathrm{THC}+\mathrm{CBD} 200 \mathrm{mg}$ per day. For acute pain attacks, additional dosing of $\mathrm{THC}+\mathrm{CBD}$ $200 \mathrm{mg}$ was allowed in both groups. In the migraine patients, the THC + CBD $200 \mathrm{mg}$ prophylaxis provided a 40.4\% improvement versus $40.1 \%$ with Amitriptyline. In the cluster headache patients, the THC + CBD $200 \mathrm{mg}$ prophylaxis gave minimal to no benefit. Additional acute $\mathrm{THC}+\mathrm{CBD} 200 \mathrm{mg}$ dosing decreased pain intensity in migraine patients by $43.5 \%$. This same result was seen in cluster headache patients, but only if they had a history of migraine in childhood. In cluster headache patients without a previous history of childhood migraine, the additional THC-CBD $200 \mathrm{mg}$ abortive treatment provided no benefit as an acute treatment.

It is unclear whether certain types of pain may respond better to certain cannabis strains with specific combinations of cannabinoids, terpenes, or other biochemical properties. There have been a multitude of studies showing benefit in many forms of chronic pain, but there have been no studies attempting to differentiate which types and strains of cannabis along with associated compositions of cannabinoids and terpenes may be more effective for certain subsets of pain. This information would be of great clinical use in providing direction for treatment recommendations by healthcare providers.

\section{Methods}

Appropriate Investigational Review Boards approved the survey. A French and English electronic survey was sent to 16,675 Tilray medicinal cannabis patients. Tilray is a federally authorized medical cannabis production, distribution, and research company in Nanaimo, British Columbia. Data gathering was performed with REDCap (Research Electronic Data Capture), a HIPAA and PIPEDA compliant secure web application for building and managing online surveys and databases. A \$10 account credit was offered to each patient completing the online survey, funded by Tilray. There was a response of 3405 (3390 English and 15 French), 2032 of which provided a verifiable Tilray patient number and were therefore included in the final analysis. The responses represent $12 \%$ of those reached. Recruitment was deliberately halted at 2000 (overlap with additional 32 subjects represents participants who were in the middle of completing the survey when it was halted). The survey launched at 9 AM PST on Monday January 9th 2017 and closed on Wednesday January 11th 2017 at 5 PM PST. The limit to responses was due to financial constraints, and patients were informed that the survey would be available for a two-week period or until limit was reached, whichever came first.

An estimation of migraine prevalence among those surveyed was obtained by incorporating the ID $\mathrm{Mi}$ graine $^{\mathrm{TM}}$ questionnaire [67] into the survey, which is used to predict the probability of migraine. In the ID Migraine $^{\mathrm{TM}}$ questionnaire, the patient is given 3 questions. If the patient answers "Yes" to 3 of these questions, there is a $97 \%$ chance they have migraine. If they answer "Yes" to 2 of these questions, there is a $93 \%$ chance they have migraine. The questions are: 1) Have your headaches interfered with your ability to work, study, or do what you needed to do? 2) Have you felt nauseated or sick to your stomach when you have a headache? 3) Does light bother you when you have a headache (a lot more than when you don't have a headache)?

Patients were asked a multitude of additional questions involving demographics, primary illnesses and symptoms treated with cannabis, frequency and quantity of use, favorite cannabis types and strains, methods of use, and prescription drugs substituted with cannabis.

Patients who reported headache as the primary illness were compared with each patient group reporting a diagnosis other than headache as the primary illness. Separately, patients who reported headache as the primary symptom (regardless of diagnosis) were compared with each patient group who both reported a diagnosis other than headache as the primary illness and also did not report headache as the primary symptom. Statistical methods were the same for each set of comparisons. Pearson chi-squared tests, or Fisher's exact tests where appropriate, were used to compare headache patients with each non-headache patient group, with regards to five cannabis strains: Hybrid, Indica, Sativa, 3:1 CBD: THC, and 1:1 CBD:THC. Significance for omnibus chisquared tests was designated by $p<.05$. When omnibus chi-squared tests were found to be significant, pairwise comparisons were carried out using a Bonferroni correction. Given ten pairwise comparisons per omnibus test, significance for each pairwise comparison was indicated by $p<.005$. Methods chosen to control for multiple comparisons allow a moderately conservative level of control, and reflect the exploratory nature of the study. Analyses were two-tailed and performed using SAS Studio v 3.5 .

\section{Results}

Of the 2032 patients included in the survey, 1271 (62.6\%) were male, 758 (37.3\%) were female, and 3 (0.15\%) did not specify gender. Ages ranged from 9 to 85 years old, with an average age of 40 . Reported ethnicities in the overall cohort revealed 1839 (90.5\%) Caucasian, 62 (3.1\%) Metis, 60 (3\%) Aboriginal/First Nation, 39 (1.9\%) Other, 37 (1.8\%) South Asian (East Indian, Pakistani, 
Sri Lankan, etc.), 35 (1.7\%) Asian (Chinese, Japanese, Korean, Vietnamese, etc.), 25 (1.2\%) Black (African, Caribbean, etc.), and 24 (1.2\%) Hispanic (Mexican, Central American, South America, etc.), with some patients reporting more than one ethnicity. Relationship status showed 833 (41\%) were married, 507 (25\%) were single and never married, 274 (13.5\%) were in a domestic partnership or civil union, 203 (10\%) were single but cohabiting with a significant other, 132 (6.5\%) were divorced, 64 (3.2\%) were separated, and 19 (0.94\%) were widowed. Habitation showed $883(43.5 \%)$ to be living in an urban area, $795(39.1 \%)$ in a suburban area, and $354(17.4 \%)$ in a rural or remote area.

There were 21 primary illnesses that were reported as being treated with medicinal cannabis, as seen in Table 1. The subsets analyzed further were headache, chronic pain, and arthritis. Chronic pain was the most frequently reported primary illness for which medicinal cannabis was being used at 29.4\% $(n=598)$, arthritis was $9.3 \%$ $(n=188)$, and headache was $3.7 \%(n=75)$. Notably, when combined these three categories of pain syndromes accounted for $42.4 \%(n=861)$ of the entire medicinal cannabis users.
Headache was then evaluated as a primary symptom being treated by medicinal cannabis across all primary illnesses (headache was the major symptom being treated with medicinal cannabis, among the primary illness categories), as seen in Table 2. There were 505 patients within the entire group surveyed (24.9\%) who reported headache as a primary symptom for which they were using medicinal cannabis across all primary illness categories. Of these patients, 262 (51.9\%) were male, 241 $(47.7 \%)$ were female, and $2(0.40 \%)$ did not specify gender. Ages ranged from 10 to 86 years old with an average age of 38. Reported ethnicities revealed 453 (89.7\%) Caucasian, 23 (4.6\%) Metis, 21 (4.2\%) Aboriginal/First Nation, 12 (2.4\%) Other, 11 (2.2\%) Hispanic (Mexican, Central American, South America, etc.), 10 (2\%) Asian (Chinese, Japanese, Korean, Vietnamese, etc.), 8 (1.6\%) South Asian (East Indian, Pakistani, Sri Lankan, etc.), and $4(0.8 \%)$ Black (African, Caribbean, etc.), with many patients reporting more than one ethnicity. Relationship status showed 181 (36\%) were married, 125 (24.8\%) were single and never married, $88(17.4 \%)$ were in a domestic partnership or civil union, $62(12.3 \%)$ were single but cohabiting with a significant other, 28 (5.5\%) were divorced, 18 (3.6\%) were separated, and $3(0.6 \%)$ were

Table 1 Primary illness treated with medicinal cannabis

\begin{tabular}{|c|c|c|c|c|}
\hline Primary IIIness & Total & Male & Female & Unspecified \\
\hline$n$ & 2032 & $1271(62.6 \%)$ & $758(37.3 \%)$ & $3(0.15 \%)$ \\
\hline Chronic Pain & $598(29.4 \%)$ & $371(62 \%)$ & $227(38 \%)$ & \\
\hline Mental Health Condition & $548(27 \%)$ & 319 (58.2\%) & $228(41.6 \%)$ & $1(0.2 \%)$ \\
\hline Insomnia/Sleep Disorder & $198(9.7 \%)$ & $145(73.2 \%)$ & $53(26.8 \%)$ & \\
\hline Arthritis/Musculoskeletal & $188(9.3 \%)$ & $112(59.6 \%)$ & 76 (40.4\%) & \\
\hline PTSD & $93(4.6 \%)$ & $59(63.4 \%)$ & $33(35.5 \%)$ & $1(1.1 \%)$ \\
\hline Headache & $75(3.7 \%)$ & $44(58.7 \%)$ & $31(41.3)$ & \\
\hline Gastrointestinal Disorder & $62(3.1 \%)$ & $34(54.8 \%)$ & $28(45.2 \%)$ & \\
\hline Multiple sclerosis & $45(2.2 \%)$ & $26(57.8 \%)$ & 19 (42.2\%) & \\
\hline Other & $38(1.9 \%)$ & $23(60.5 \%)$ & 15 (39.5\%) & \\
\hline Cancer/Leukemia & $35(1.7 \%)$ & $24(68.6 \%)$ & $11(31.4 \%)$ & \\
\hline Crohn's Disease & $35(1.7 \%)$ & $27(77.1 \%)$ & $8(22.9 \%)$ & \\
\hline Brain Injury & $24(1.3 \%)$ & $16(66.7 \%)$ & $8(33.3 \%)$ & \\
\hline Epilepsy/Seizure Disorder & $21(1.0 \%)$ & $18(85.7 \%)$ & $3(14.3 \%)$ & \\
\hline Eating Disorder & $20(1.0 \%)$ & $10(50 \%)$ & $10(50 \%)$ & \\
\hline Diabetes & $16(0.79 \%)$ & $13(81.3 \%)$ & $3(18.7 \%)$ & \\
\hline Movement Disorder & $10(0.49 \%)$ & $8(80 \%)$ & $1(10 \%)$ & $1(10 \%)$ \\
\hline AIDS/HIV & $8(0.39 \%)$ & 7 (87.5\%) & $1(12.5 \%)$ & \\
\hline Hepatitis & $6(0.30 \%)$ & $6(100 \%)$ & $0(0 \%)$ & \\
\hline Glaucoma & $5(0.25 \%)$ & $5(100 \%)$ & $0(0 \%)$ & \\
\hline Osteoporosis & $4(0.20 \%)$ & $3(75 \%)$ & $1(25 \%)$ & \\
\hline Skin Condition & $3(0.15 \%)$ & $1(33.3 \%)$ & $2(66.7 \%)$ & \\
\hline
\end{tabular}


Table 2 Headache as primary symptom treated with medicinal cannabis among various primary illnesses reported

\begin{tabular}{|c|c|c|c|c|}
\hline Primary IIIness & Total & Male & Female & Unspecified \\
\hline$n$ & 505 & $262(51.9 \%)$ & $241(47.7 \%)$ & $2(0.40 \%)$ \\
\hline Chronic pain & $148(29.3 \%)$ & 70 (47.3\%) & 78 (52.7\%) & \\
\hline Mental Health Condition & $131(25.9 \%)$ & 65 (49.6\%) & $66(50.4 \%)$ & \\
\hline Headache & 75 (14.9\%) & $44(58.7 \%)$ & $31(41.3 \%)$ & \\
\hline Insomnia & $32(6.3 \%)$ & $25(78.1 \%)$ & $7(21.9 \%)$ & \\
\hline Arthritis/Musculoskeletal & $29(5.7 \%)$ & $12(41.4 \%)$ & $17(58.6 \%)$ & \\
\hline PTSD & $24(4.8 \%)$ & $9(37.5 \%)$ & $14(58.3 \%)$ & $1(4.2 \%)$ \\
\hline MS & $13(2.6 \%)$ & $3(23.1 \%)$ & $10(76.9 \%)$ & \\
\hline Brain Injury & $12(2.4 \%)$ & $8(66.7 \%)$ & $4(33.3 \%)$ & \\
\hline Gastrointestinal Disorder & $11(2.2 \%)$ & $5(45.5 \%)$ & $6(54.5 \%)$ & \\
\hline Cancer/Leukemia & $6(1.2 \%)$ & $3(50 \%)$ & $3(50 \%)$ & \\
\hline Movement Disorder & $5(1.0 \%)$ & $4(80 \%)$ & $0(0 \%)$ & $1(20 \%)$ \\
\hline Other & $4(0.79 \%)$ & $2(50 \%)$ & $2(50 \%)$ & \\
\hline Epilepsy/Seizure Disorder & $3(0.59 \%)$ & $2(66.7 \%)$ & $1(33.3 \%)$ & \\
\hline Crohn's Disease & $3(0.59 \%)$ & $3(100 \%)$ & $0(0 \%)$ & \\
\hline Diabetes & $2(0.40 \%)$ & $1(50 \%)$ & $1(50 \%)$ & \\
\hline Glaucoma & $2(0.40 \%)$ & $2(100 \%)$ & $0(0 \%)$ & \\
\hline Hepatitis & $2(0.40 \%)$ & $2(100 \%)$ & $0(0 \%)$ & \\
\hline Eating Disorder & $1(0.20 \%)$ & $1(100 \%)$ & $0(0 \%)$ & \\
\hline AIDS/HIV & $1(0.20 \%)$ & $1(100 \%)$ & $0(0 \%)$ & \\
\hline Osteoporosis & $1(0.20 \%)$ & $0(0 \%)$ & $1(100 \%)$ & \\
\hline
\end{tabular}

widowed. Habitation showed 218 (43.2\%) to be living in an urban area, $205(40.6 \%)$ in a suburban area, and 82 $(16.2 \%)$ in a rural or remote area. Chronic pain was the most common primary illness in which headache was reported to be a primary symptom being treated with medicinal cannabis (29.3\%), followed by mental health condition (25.9\%) and headache (14.9\%).

The 505 patients who reported headache as a primary symptom being treated by medicinal cannabis were then analyzed to estimate how many of those patients had probable migraine, and thus, how many were using medicinal cannabis for probable migraine management. This data was obtained via responses to the ID Migraine ${ }^{\mathrm{Tm}}$ questionnaire. There were 343 (68\%) who gave 3 "Yes" responses, and 102 (20\%) who gave 2 "Yes" responses. Based on these responses, 445 of these 505 patients $(88 \%)$ had a very high probability between 93 and $97 \%$ that the headaches they were treating with medicinal cannabis represented migraine.

Data was collected among patients to determine the most commonly used and preferred types of cannabis, as well as preferred specific strains. The preferred types of cannabis included Indica, Sativa, Hybrid, 3:1 CBD:THC, or 1:1 CBD:THC. Indicas, Sativas and Hybrids were all high THC/low CBD strains or extracts, while 1:1 and 3:1 strains and extracts represent the CBD:THC ratio, and were considered high CBD strains. The Indica, Sativa, and Hybrid types were further divided into specific strains within each of these cannabis types.

There were 42 different preferred treatment strains reported by patients and these included: Afghani, Afghani CBD, Alien OG, Barbara Bud, Black Tuna, Blueberry, Bubba Kush, Cannatonic, CBD House Blend, Cheese, Churchill, Dig Weed, Elwyn, Green Cush, Girl Scout Cookies (GSC), Harmony, Headband, Hybrid House Blend, Indica House Blend, Island Sweet Skunk, Jack Herer, Jean Guy, Lemon Sour Diesel, Limonene House Blend, Mango, Master Kush, Myrcene Blend, OG Kush, OG Shark, Pinene House Blend, Pink Kush, Purple Kush, Rockstar, Sativa House Blend, Sirius, Strawberry Cough (SBC), Skywalker OG, Sour Diesel, Sweet Skunk CBD, Warlock CBD, Watermelon, and White Widow.

Preferred cannabis types and strains were first analyzed between the headache as primary symptom, headache as primary illness, chronic pain as primary illness, and arthritis as primary illness groups. Hybrid strains were the most commonly preferred cannabis types across all pain groups. However, when patients with headache as a primary symptom were excluded from the groups, the arthritis group preferred Indica strains, while the others still preferred Hybrid strains. The top 15 preferred cannabis strains within each of these pain groups are seen in Tables 3 and 5. Preferred cannabis types and 


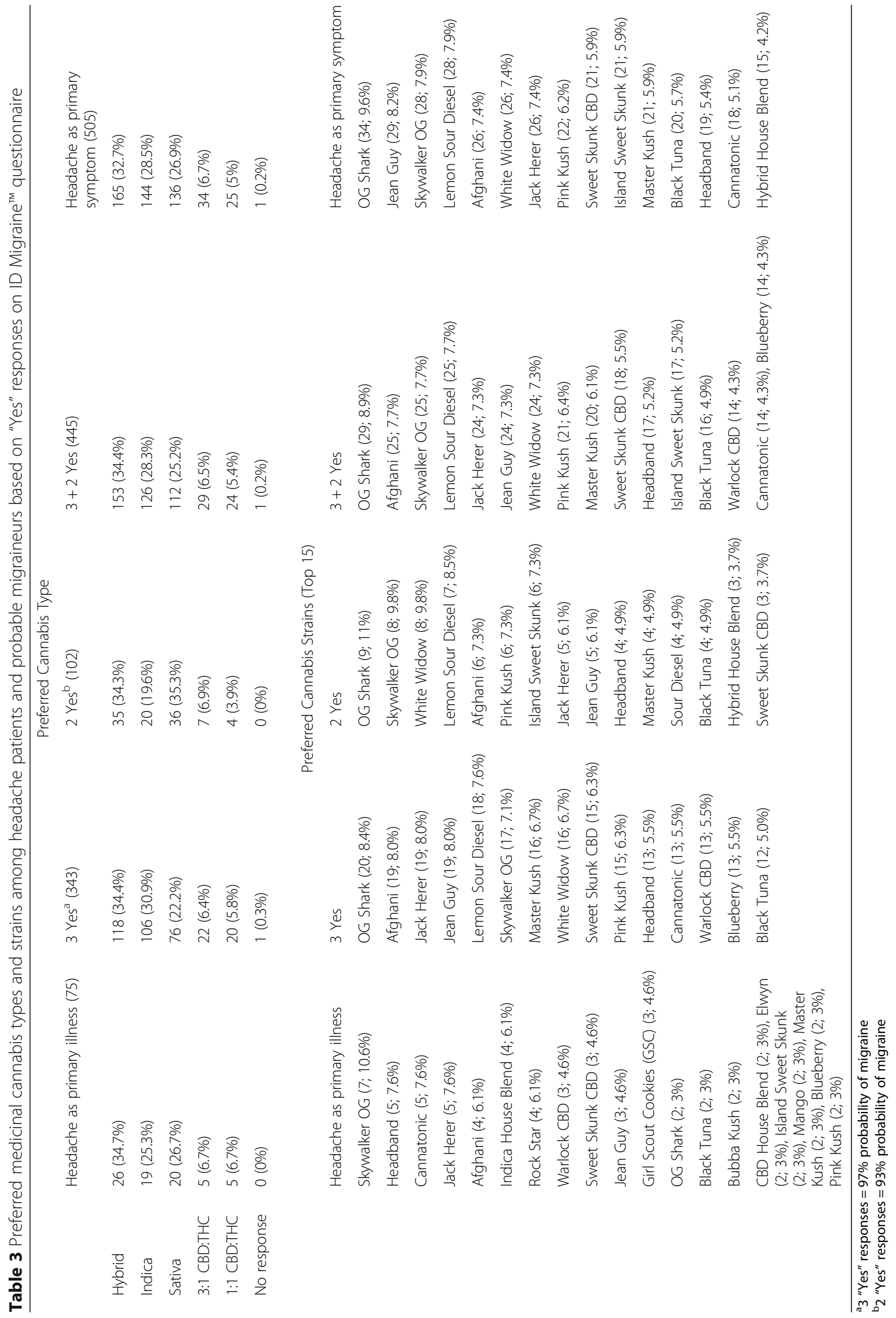


strains were then analyzed in the positive ID Migraine ${ }^{\mathrm{Tx}}$ patients who answered 3 "Yes" responses (343), 2 "Yes" responses (102), or combined $3+2$ "Yes" responses (445) to the ID Migraine ${ }^{\mathrm{Tw}}$ questionnaire. Thus, they were the most probable group of headache patients who were treating migraine with medicinal cannabis. Hybrid strains were the most commonly preferred cannabis types across the positive ID Migraine ${ }^{\mathrm{Tx}}$ groups with the exception that the 2 "Yes" group had a slight preference for Sativa, followed by Hybrid strains. The top 15 preferred cannabis strains within each positive ID Migrain $^{\mathrm{Tm}}$ group are seen in Table 3. "OG Shark" was the most commonly preferred strain across all of the positive ID Migraine $^{\mathrm{Tm}}$ and headache as primary symptom groups. Quantification and comparison of the cannabinoids and terpenes present in these top 15 preferred strains is seen in Table 4. The cannabinoids analyzed were $\Delta^{9}$ tetrahydrocannabinol (THC), tetrahydrocannabinolic acid (THCA), cannabidiol (CBD), and cannabidiolic acid (CBDA). The terpenes analyzed were $\alpha$-pinene, $\beta$ myrcene, D-limonene, linalool, $\beta$-caryophyllene, humulene, trans-nerolidol, and bisabolol. Notably, "OG Shark", a high THC/THCA, low CBD/CBDA strain with $\beta$-caryophyllene followed by $\beta$-myrcene as the predominant terpenes, was the most preferred strain in both the positive ID Migraine ${ }^{\mathrm{Tx}}$ and headache as primary symptom groups.

For further comparison purposes, preferred cannabis types and strains were also analyzed for the three most common non-pain subsets of patients, which included mental health condition/PTSD, insomnia/sleep disorder, gastrointestinal disorder/Crohn's Disease, and the overall patient cohort, as seen in Table 5. Indica strains were preferred in the insomnia/sleep disorders group, Sativa strains in the mental health condition/PTSD group, and Hybrid strains in the gastrointestinal disorder/Crohn's Disease group, regardless of whether patients with headache as a primary symptom were included or not. Table 6 shows these same groups, as well as the arthritis and chronic pain groups, with all groups excluding patients with headache as a primary symptom.

Statistical analysis was performed to determine if there were significant differences in preferred cannabis types reported by headache patients. The data were insufficient for statistical analysis of specific strain preferences. There were no statistically significant differences found between patients with headache as primary illness and those with chronic pain, arthritis, or mental health condition/PTSD. When compared to insomnia/sleep disorder patients, headache as primary illness patients were 7.7 times as likely to prefer 3:1 CBD:THC over Indica (OR 7.7, 95\% CI 1.7-35.11, $p=.003$ ).

Patients with headache as primary symptom were 2.7 times as likely to prefer Sativa over 1:1 CBD:THC (OR $2.66,95 \%$ CI 1.52-4.66, $p<.001)$ when compared to chronic pain patients. When compared to arthritis patients, headache as primary symptom patients were 3.4 times as likely to prefer Sativa over 1:1: CBD:THC (OR 3.35, 95\% CI 1.57-7.12, $p=.001$ ). When compared to insomnia patients, headache as primary symptom

Table 4 Terpenes and cannabinoids present in top 15 preferred medicinal cannabis strains in headache patients who replied with 3 or 2 "Yes" responses on ID Migraine ${ }^{\mathrm{TM}}$ questionnaire

\begin{tabular}{|c|c|c|c|c|c|c|c|c|c|c|c|c|}
\hline \multirow[t]{2}{*}{ Strain } & \multicolumn{8}{|c|}{ Terpenes (\%) } & \multicolumn{4}{|c|}{ Cannabinoids (\%) } \\
\hline & a-Pinene & $\beta$-Myrcene & D-Limonene & Linalool & $\beta$-Caryophyllene & Humulene & $\begin{array}{l}\text { Trans- } \\
\text { nerolidol }\end{array}$ & Bisabolol & THCA & $\mathrm{THC}$ & CBDA & $\mathrm{CBD}$ \\
\hline OG Shark & 0.022 & 0.194 & 0.191 & 0.136 & 0.263 & 0.078 & 0.023 & 0.107 & 22.8 & 21.4 & 0.1 & 0 \\
\hline Afghani & 0.024 & 0.101 & 0.036 & 0.033 & 0.132 & 0.055 & 0.032 & 0.066 & 16.9 & 15.6 & 0.1 & 0 \\
\hline Skywalker OG & 0.037 & 0.217 & 0.208 & 0.159 & 0.319 & 0.149 & 0.024 & 0.110 & 24.2 & 22.9 & 0.2 & 0 \\
\hline Lemon Sour Diesel & 0.127 & 0.235 & 0.037 & 0.026 & 0.169 & 0.067 & 0.022 & 0.026 & 19.9 & 18.3 & 0.1 & 0 \\
\hline Jack Herer & 0.369 & 0.612 & 0.023 & 0.021 & 0.132 & 0.039 & 0.046 & 0.013 & 18.8 & 17.9 & 0.2 & 0 \\
\hline Jean Guy & 0.031 & 0.066 & 0.069 & 0.063 & 0.156 & 0.047 & 0.050 & 0.052 & 18.1 & 17.3 & 0.1 & 0 \\
\hline White Widow & 0.032 & 0.093 & 0.195 & 0.006 & 0.106 & 0.032 & 0.034 & 0.051 & 20.1 & 18.7 & 0.1 & 0 \\
\hline Pink Kush & 0.019 & 0.187 & 0.178 & 0.148 & 0.317 & 0.093 & 0.058 & 0.124 & 27.7 & 25.8 & 0.1 & 0 \\
\hline Master Kush & 0.045 & 0.168 & 0.192 & 0.203 & 0.353 & 0.169 & 0.039 & 0.130 & 28 & 25.6 & 0.1 & 0 \\
\hline Sweet Skunk CBD & 0.054 & 0.162 & 0.042 & 0.014 & 0.051 & 0.019 & 0.015 & 0.028 & & 9.1 & & 11.2 \\
\hline Headband & 0.028 & 0.238 & 0.230 & 0.138 & 0.318 & 0.094 & 0.065 & 0.124 & 25.1 & 23.4 & 0.1 & 0 \\
\hline Black Tuna & 0.026 & 0.139 & 0.149 & 0.077 & 0.267 & 0.088 & 0.033 & 0.054 & 21.8 & 0.2 & 0.1 & 0 \\
\hline Warlock CBD & 0.050 & 0.298 & 0.199 & 0.051 & 0.173 & 0.102 & 0.023 & 0.032 & 11.4 & 11 & 12.6 & 11.4 \\
\hline Cannatonic & 0.059 & 0.152 & 0.038 & 0.022 & 0.099 & 0.032 & 0.015 & 0.035 & 10.9 & 9.4 & 7.6 & 7.5 \\
\hline Blueberry & 0.000 & 0.333 & 0.000 & 0.052 & 0.324 & 0.089 & 0.021 & 0.023 & & 21.7 & & 0.1 \\
\hline
\end{tabular}




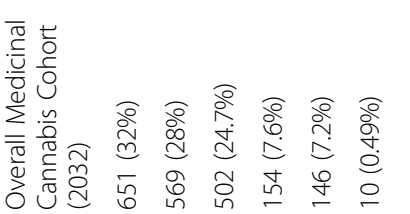

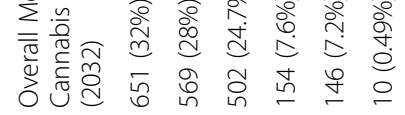

空

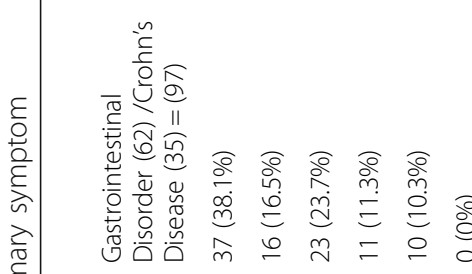

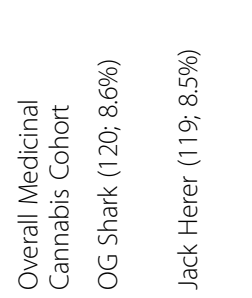

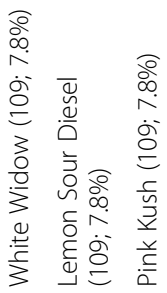

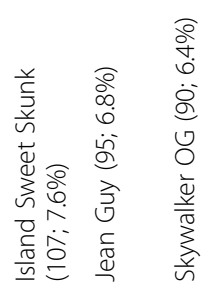

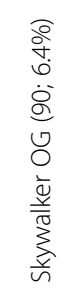

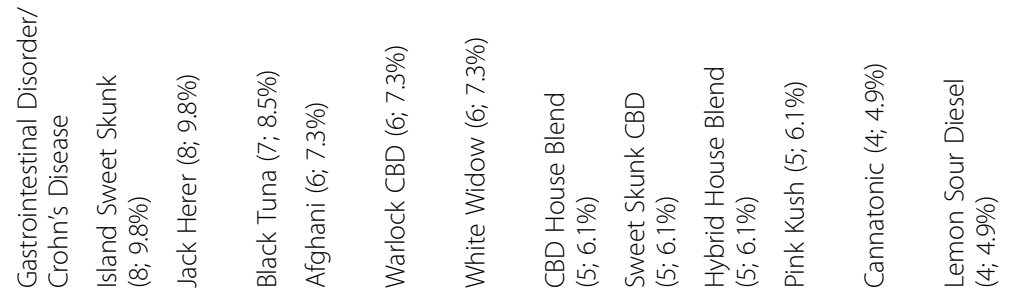

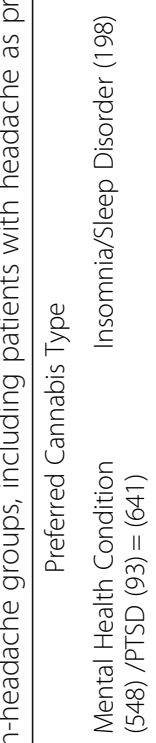

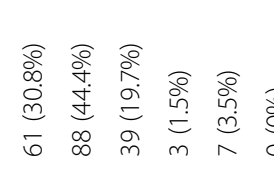

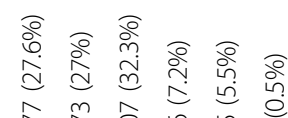<smiles></smiles>

$\frac{\bar{v}}{\overline{0}}$

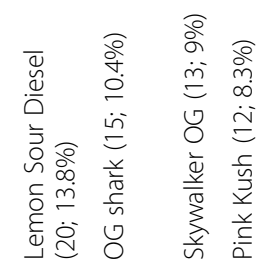

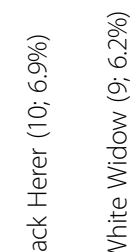

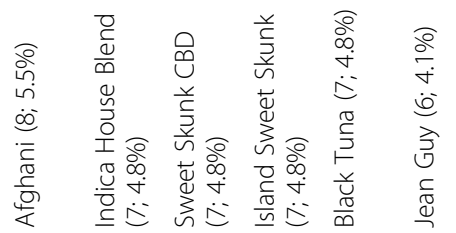

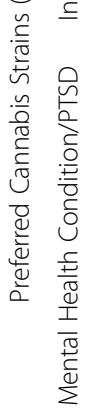

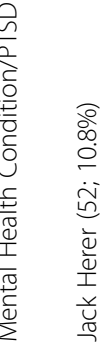

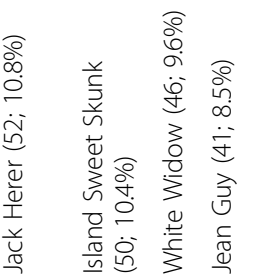

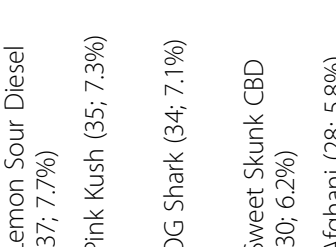

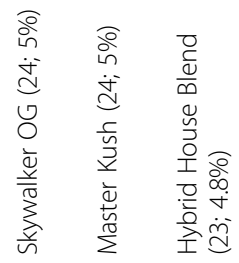

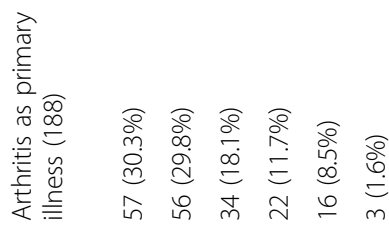

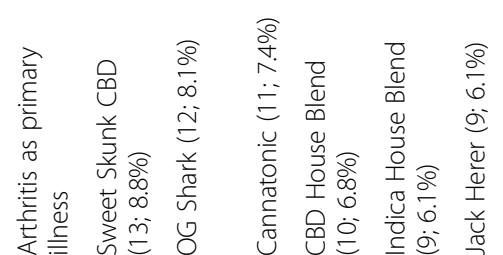

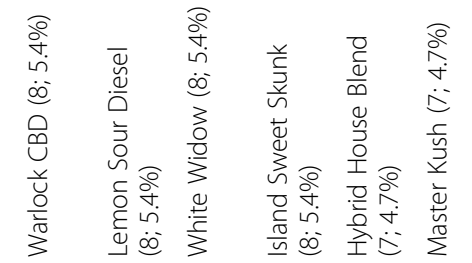

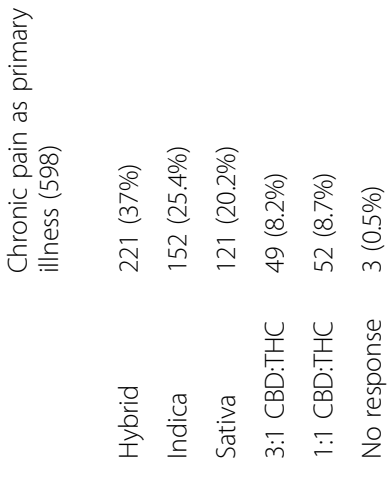




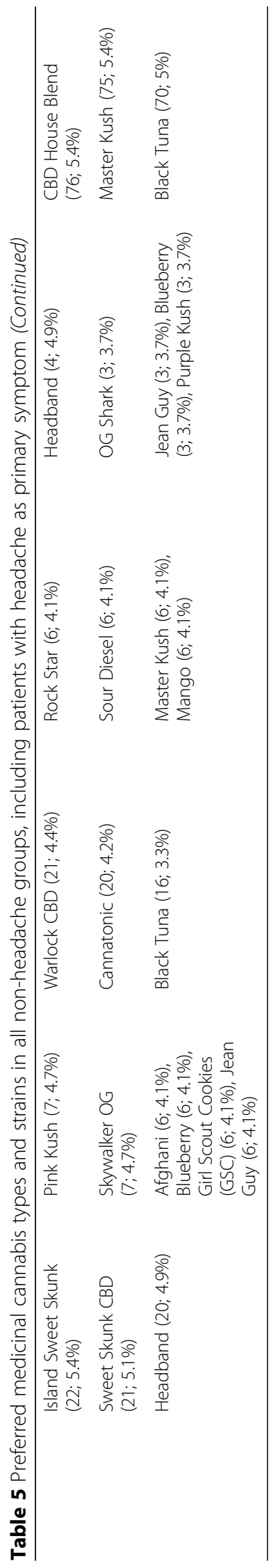


줄 늠

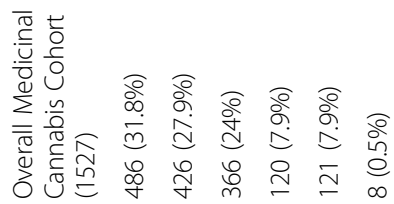

혼

票觉

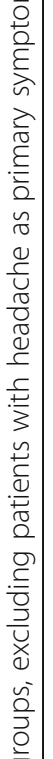

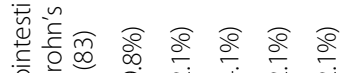

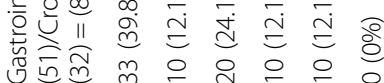

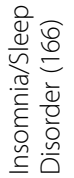
물

递存要

要

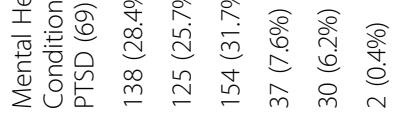

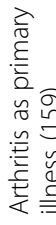

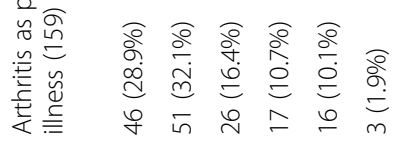

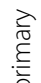

$\frac{2}{n}$

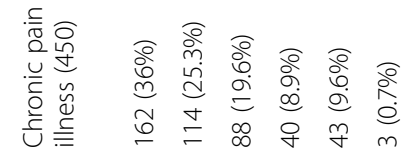

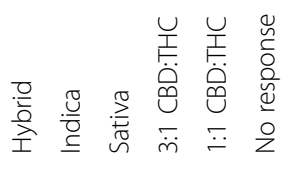

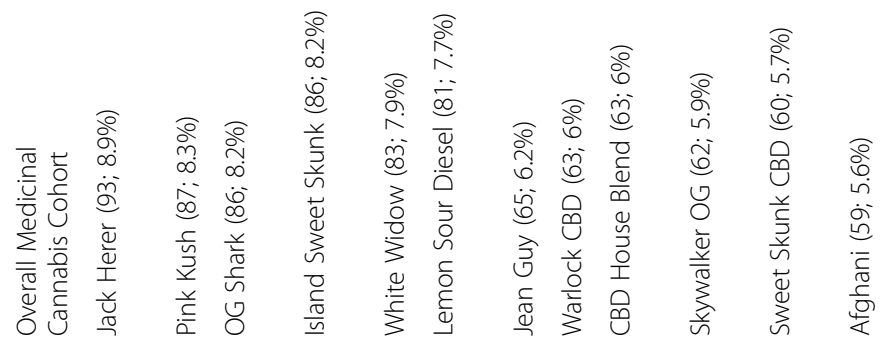

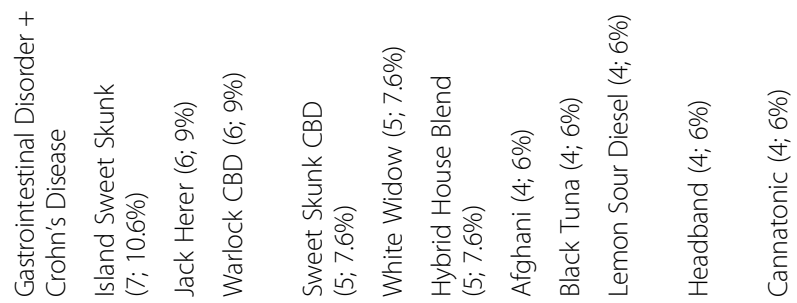

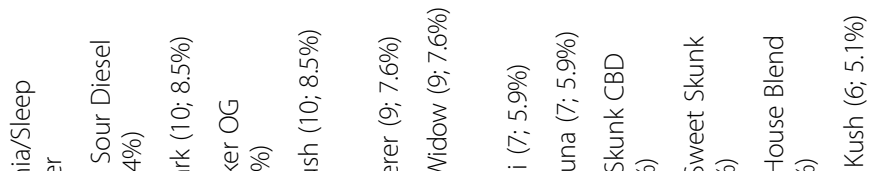

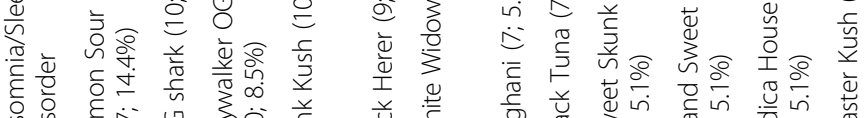

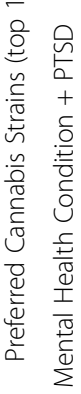

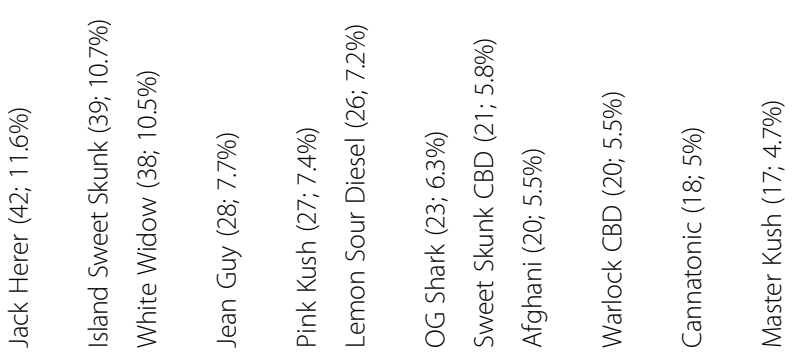

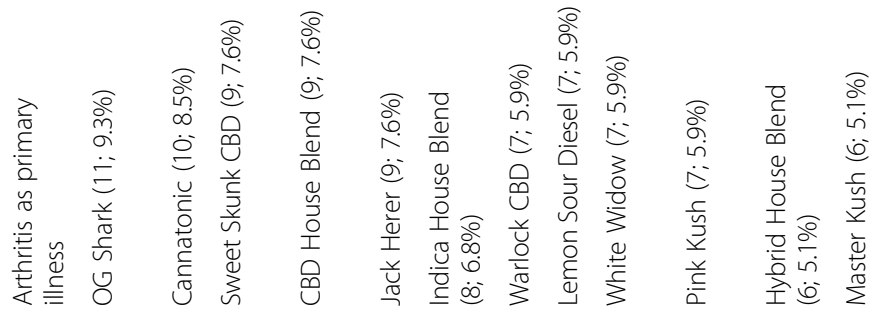

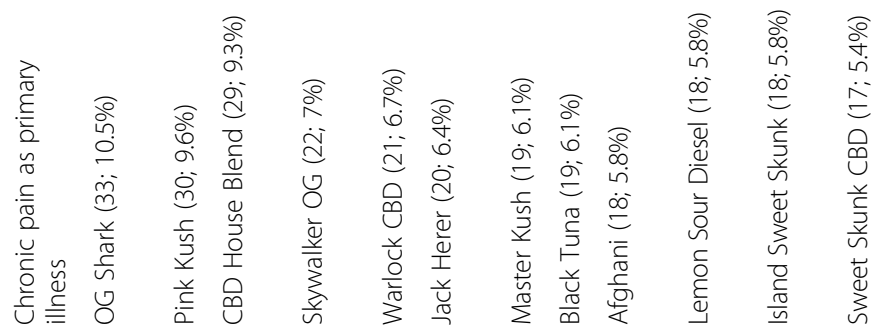




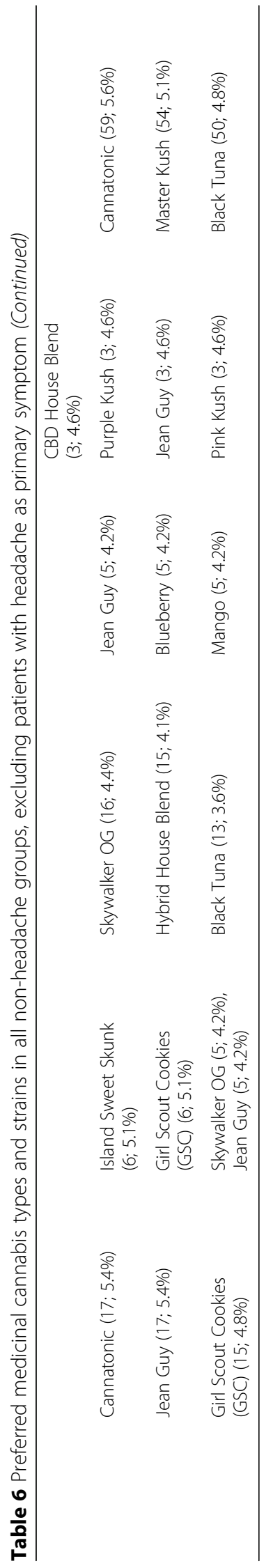


patients were over twice as likely to prefer Sativa over Indica (OR 2.18, 95\% CI 1.36-3.52, $p=.001$ ) and 8.7 times as likely to prefer 3:1 CBD:THC over Indica (OR 8.74, 95\% CI 2.04-37.37, $p<.001$ ). When compared to gastrointestinal disorder/Crohn's disease patients, headache as primary symptom patients were almost three times as likely to prefer Indica over Hybrid (OR $2.88,95 \%$ CI 1.37-6.05, $p=.004), 4.2$ times as likely to prefer Indica over 3:1 CBD:THC (OR 4.24, 95\% CI 1.63-10.98, $p=.002)$, and 5.8 times as likely to prefer Indica over 1:1 THC:CBD (OR 5.76, 95\% CI 2.17-15.26, $p<.001)$. There were no statistically significant differences found between headache as primary symptom patients and mental health condition/PTSD patients, nor between all non-headache patients as a group.

A number of variables were assessed across all pain groups. These variables included primary method of cannabis use, prevalence of cannabis extract (drops, capsules) use and preferences, cannabis quantity and frequency of use, highest level of education completed, employment status, and prescription medications replaced with medicinal cannabis. The most common primary methods of use across all pain groups were vaporizing and joint use, although additional methods included waterpipe/bong, oral (edibles such as oil drops/extracts, baked goods, butter, tincture), pipe, juicing, tea, or topical use, as seen in Table 7. In the 505 patients with headache as a primary symptom, the most common primary methods of use were joint in 170 (33.7\%), and vaporizing in $162(32.1 \%)$, and this pattern was similar in the positive ID Migraine $^{\mathrm{rm}}$ groups. In general, primary methods of use were similar to the top non-pain related primary illnesses, and the overall patient cohort.

The majority of patients using cannabis extracts (drops, capsules) across pain groups preferred the 3:1 CBD:THC extract with the exception that the chronic pain group preferred 1:1 CBD:THC extract, the 3 "Yes" positive ID Migraine ${ }^{\mathrm{ma}}$ group preferred Indica extract, and the combined $3+2$ "Yes" positive ID Migraine group equally preferred 3:1 CBD:THC and Indica extracts, as seen in Table 8. Overall, in the headache as primary symptom group, 195 (38.6\%) were using cannabis extracts, and the 3:1 CBD:THC extract was most commonly used in $53(27.2 \%)$ followed by the Indica extract in 51 (26.2\%).

Quantity of cannabis used was estimated as one joint $=0.3-0.5 \mathrm{~g}$, one eighth $=3.5 \mathrm{~g}$, one quarter $=7 \mathrm{~g}$, and one ounce $=28 \mathrm{~g}$. The quantity and frequency of medicinal cannabis use across the groups ranged from 9.6-11.4 g/week, 1.4-1.7 g/day, 0.58-0.76 g/treatment, 5.9-6.5 days/week and 3.2-3.9 times/day. The quantity of medicinal cannabis use in the headache group averaged $11.4 \mathrm{~g} /$ week, $1.7 \mathrm{~g} /$ day, and $0.66 \mathrm{~g} /$ treatment, with a frequency of 6.4 days/week, and 3.9 times/day. The positive ID Migraine ${ }^{\mathrm{Tm}}$ patients averaged similar patterns of use, although at the upper ranges of use. These results can all be seen in Table 9 .

Table 7 Primary method of medicinal cannabis use among various pain syndromes, "Yes" responses on ID Migraine ${ }^{\mathrm{TM}}$ questionnaire, top non-pain related primary illnesses, and overall cohort

\begin{tabular}{|c|c|c|c|c|c|c|c|c|}
\hline \\
\hline & \multicolumn{8}{|c|}{$\begin{array}{l}\text { Primary method of use } \\
\text { Vaporizer }\end{array}$} \\
\hline \multicolumn{9}{|c|}{$\begin{array}{llllllll}\begin{array}{l}\text { Headache as primary } \\
\text { symptom }(505)\end{array} & 162(32.1 \%) & 50(9.9 \%) & 170(33.7 \%) & 58(11.5 \%) & 63(12.5 \%) & 1(0.2 \%) & 1(0.2 \%)\end{array}$} \\
\hline \multicolumn{9}{|l|}{$\begin{array}{l}\text { symptom (505) } \\
\text { Headache as primary } \\
\text { illness (75) }\end{array}$} \\
\hline $\begin{array}{l}\text { Chronic pain as primary } \\
\text { illness (598) }\end{array}$ & 179 (29.9\%) & $56(9.4 \%)$ & $183(30.6 \%)$ & $120(20.1 \%)$ & $56(9.4 \%)$ & \multicolumn{2}{|l|}{$1(0.17 \%)$} & $3(0.5 \%)$ \\
\hline $\begin{array}{l}\text { Arthritis as primary } \\
\text { illness (188) }\end{array}$ & $70(37.2 \%)$ & $16(8.5 \%)$ & $60(31.9 \%)$ & $36(19.2 \%)$ & $4(2.1 \%)$ & & & \multirow[t]{4}{*}{$2(1.1 \%)$} \\
\hline 3 Yes $(343)^{a}$ & $109(31.8 \%)$ & $37(10.8 \%)$ & $120(35 \%)$ & $37(10.8 \%)$ & $39(11.4 \%)$ & & \multirow[t]{3}{*}{$1(0.29 \%)$} & \\
\hline 2 Yes $(102)^{b}$ & $34(33.3 \%)$ & $9(8.8 \%)$ & $29(28.4 \%)$ & $11(10.8 \%)$ & $19(18.6 \%)$ & & & \\
\hline $3+2$ Yes (445) & $143(32.1 \%)$ & $46(10.3 \%)$ & 149 (33.5\%) & $48(10.8 \%)$ & $58(13 \%)$ & & & \\
\hline $\begin{array}{l}\text { Mental Health Condition } \\
(548)+\text { PTSD (93) }\end{array}$ & $184(28.7 \%)$ & $89(13.9 \%)$ & 195 (30.4\%) & $74(11.5 \%)$ & $97(15.1 \%)$ & $1(0.16 \%)$ & \multirow[t]{3}{*}{$1(0.16 \%)$} & \\
\hline Insomnia/Sleep Disorder (198) & $63(31.8 \%)$ & 19 (9.6\%) & $65(32.8 \%)$ & $30(15.2 \%)$ & $19(9.6 \%)$ & \multirow[t]{2}{*}{$1(0.51 \%)$} & & \multirow[t]{2}{*}{$1(0.51 \%)$} \\
\hline $\begin{array}{l}\text { Gastrointestinal Disorder } \\
(62)+\text { Crohn's Disease (35) }\end{array}$ & $34(35.1 \%)$ & $12(12.4 \%)$ & $26(26.8 \%)$ & $11(11.3 \%)$ & $14(14.4 \%)$ & & & \\
\hline $\begin{array}{l}\text { Overall Medicinal Cannabis } \\
\text { Cohort (2032) }\end{array}$ & $632(31.1 \%)$ & $229(11.3 \%)$ & $617(30.4 \%)$ & $330(16.2 \%)$ & $212(10.4 \%)$ & $4(0.20 \%)$ & $2(0.10 \%)$ & $6(0.30 \%)$ \\
\hline
\end{tabular}

${ }^{\text {a } 3 ~ " Y e s " ~ r e s p o n s e s ~}=97 \%$ probability of migraine

$b_{2}$ "Yes" responses $=93 \%$ probability of migraine 
Table 8 Medicinal cannabis extract use preferences among various pain syndromes and "Yes" responses on ID Migraine ${ }^{\mathrm{TM}}$ questionnaire

\begin{tabular}{|c|c|c|c|c|c|c|}
\hline \multicolumn{7}{|l|}{ Cannabis extracts (drops, capsules) } \\
\hline & Total & Hybrid & Indica & Sativa & 3:1 CBD:THC & 1:1 CBD:THC \\
\hline Headache as primary symptom (505) & $195(38.6 \%)$ & $36(18.5 \%)$ & $51(26.2 \%)$ & $15(7.7 \%)$ & $53(27.2 \%)$ & $40(20.5 \%)$ \\
\hline Headache as primary illness (75) & $26(34.7 \%)$ & 7 (26.9\%) & $5(19.2 \%)$ & $1(3.9 \%)$ & $9(34.6 \%)$ & $4(15.4 \%)$ \\
\hline Chronic pain as primary illness (598) & $248(41.5 \%)$ & $44(17.7 \%)$ & $56(22.6 \%)$ & $18(7.3 \%)$ & $60(24.2 \%)$ & $66(26.6 \%)$ \\
\hline Arthritis as primary illness (188) & $80(42.6 \%)$ & $14(17.5 \%)$ & $11(13.8 \%)$ & $5(6.3 \%)$ & $26(32.5 \%)$ & $24(30 \%)$ \\
\hline 3 Yes $(343)^{a}$ & $143(41.7 \%)$ & $25(17.5 \%)$ & $41(28.7 \%)$ & $6(4.2 \%)$ & $39(27.3 \%)$ & $32(22.4 \%)$ \\
\hline 2 Yes $(102)^{b}$ & $33(32.4 \%)$ & $6(18.2 \%)$ & $7(21.2 \%)$ & $5(15.2 \%)$ & $9(27.3 \%)$ & $6(18.2 \%)$ \\
\hline $3+2$ Yes (445) & $176(39.6 \%)$ & $31(17.6 \%)$ & $48(27.3 \%)$ & $11(6.3 \%)$ & $48(27.3 \%)$ & $38(21.6 \%)$ \\
\hline
\end{tabular}

${ }^{3}$ "Yes" responses $=97 \%$ probability of migraine

${ }^{b} 2$ "Yes" responses $=93 \%$ probability of migraine

The highest level of education completed across medicinal cannabis user groups can be seen in Table 10 . Options included graduate degree, university degree (Bachelors' degree or equivalent), some college/university but no degree/certificate, technical/non-university degree, high school degree or equivalent (GED), and less than high school degree. The most common education level completed across all pain groups was technical/ non-university degree, including the headache group, $n=158$ (31.3\%). The exception was in the 2 "Yes" positive ID Migraine ${ }^{\mathrm{Tu}}$ group, which most commonly reported some college/university but no degree/certificate.

Employment status among medicinal cannabis users was assessed, and can be seen in Table 10. The options were employed working full-time, employed working part-time, retired, not employed looking for work, not employed not looking for work, and disabled not able to work. The vast majority of patients across all pain groups were employed working full time, including the headache group, $n=268$ (53.1\%).

Prescription medications that were replaced with medicinal cannabis were also recorded, as seen in Table 11, and included opiates/opioids, NSAIDs/analgesics, triptans, ergots, anti-depressant/anti-anxiety, anti-convulsant, and muscle relaxers. Many patients across all groups had replaced prescription medications with medicinal cannabis, including headache as primary symptom $n=272$ (53.9\%). Ranges of prescription medication replacement across pain groups varied between $41.2 \%-59.5 \%$ of patients. The most common prescription medications replaced by medicinal cannabis were opiates/opioids in every pain group, including headache as primary symptom $n=118$ (43.4\%). Ranges of opiate/opioid replacement across pain groups varied between $40.5 \%-72.8 \%$ of patients. Notably, additional prescription medications replaced by medicinal cannabis in headache patients included $106(39 \%)$ antidepressant/anti-anxiety, 57 (21\%) NSAIDs, 22 (8.1\%) triptans, 21 (7.7\%) anticonvulsants, 19 (7\%) muscle relaxers, and 1 (0.4\%) ergots.

\section{Discussion}

The neurobiological pathways of cannabinoids and pain, including migraine and headache, have been detailed, summarized and should be reviewed [1, 2, 51, 65, 68-70]. Briefly, the endocannabinoid system is distributed throughout the central and peripheral nervous system, is involved

Table 9 Quantity and frequency of medicinal cannabis use among various pain syndromes and "Yes" responses on ID Migraine ${ }^{\mathrm{TM}}$ questionnaire

\begin{tabular}{llllll}
\hline Cannabis quantity and frequency used & & & & \\
\hline & $\begin{array}{l}\text { Grams per week } \\
\text { (Average) }\end{array}$ & $\begin{array}{l}\text { Grams per day } \\
\text { (Average) }\end{array}$ & $\begin{array}{l}\text { Grams per treatment } \\
\text { (Average) }\end{array}$ & $\begin{array}{l}\text { Days used per week } \\
\text { (Average) }\end{array}$ & $\begin{array}{l}\text { Times used per day } \\
\text { (Average) }\end{array}$ \\
\hline Headache as primary symptom (505) & 1 to $>28(11.4)$ & $\leq 0.25$ to $\geq 4(1.7)$ & $\leq 0.25$ to $\geq 4(0.66)$ & $1-7(6.4)$ & 1 to $>10(3.9)$ \\
Headache as primary illness (75) & 1 to $>28(9.6)$ & $\leq 0.25$ to $\geq 4(1.4)$ & $\leq 0.25$ to $\geq 4(0.67)$ & $1-7(5.9)$ & 1 to $>10(3.3)$ \\
Chronic pain as primary illness (598) & 1 to $>28(10.8)$ & $\leq 0.25$ to $\geq 4(1.6)$ & $\leq 0.25$ to $\geq 4(0.68)$ & $1-7(6.2)$ & 1 to $>10(3.7)$ \\
Arthritis as primary illness (188) & 1 to $>28(9.8)$ & $\leq 0.25$ to $\geq 4(1.4)$ & $\leq 0.25$ to $\geq 4(0.58)$ & $1-7(6.1)$ & 1 to $>10(3.2)$ \\
3 Yes (343) & 1 to $>28(11.2)$ & $\leq 0.25$ to $\geq 4(1.7)$ & $\leq 0.25$ to $\geq 4(0.63)$ & $1-7(6.4)$ & 1 to $>10(3.9)$ \\
2 Yes (102) & 1 to $>28(11.3)$ & $\leq 0.25$ to $\geq 4(1.7)$ & $\leq 0.25$ to $\geq 4(0.76)$ & $1-7(6.5)$ & 1 to $>10(3.8)$ \\
$3+2$ Yes (445) & 1 to $>28(11.3)$ & $\leq 0.25$ to $\geq 4(1.7)$ & $\leq 0.25$ to $\geq 4(0.70)$ & $1-7(6.5)$ & 1 to $>10(3.9)$ \\
\hline
\end{tabular}

${ }^{\mathrm{a}} 3$ "Yes" responses $=97 \%$ probability of migraine

${ }^{b_{2}} 2$ "Yes" responses $=93 \%$ probability of migraine 
Table 10 Highest education level completed and employment status in medicinal cannabis users among various pain syndromes and "Yes" responses on ID Migraine ${ }^{T M}$ questionnaire

\begin{tabular}{|c|c|c|c|c|c|c|}
\hline \multicolumn{7}{|c|}{ Highest level of education completed } \\
\hline & Graduate degree & $\begin{array}{l}\text { University degree } \\
\text { (Bachelors' degree } \\
\text { or equivalent) }\end{array}$ & $\begin{array}{l}\text { Some college/ } \\
\text { university, but no } \\
\text { degree/certificate }\end{array}$ & $\begin{array}{l}\text { Technical and } \\
\text { non-university } \\
\text { degree }\end{array}$ & $\begin{array}{l}\text { High school degree } \\
\text { or equivalent (GED) }\end{array}$ & $\begin{array}{l}\text { Less than high } \\
\text { school degree }\end{array}$ \\
\hline All patients (2032) & $122(6 \%)$ & $322(15.9 \%)$ & $432(21.3 \%)$ & $642(31.6 \%)$ & $375(18.5 \%)$ & $139(6.8 \%)$ \\
\hline $\begin{array}{l}\text { Headache as primary } \\
\text { symptom (505) }\end{array}$ & $17(3.4 \%)$ & $81(16 \%)$ & $124(24.6 \%)$ & $158(31.3 \%)$ & $91(18 \%)$ & $34(6.7 \%)$ \\
\hline $\begin{array}{l}\text { Headache as primary } \\
\text { illness (75) }\end{array}$ & $5(6.7 \%)$ & $18(24 \%)$ & $16(21.3 \%)$ & $22(29.3 \%)$ & $9(12 \%)$ & $5(6.7 \%)$ \\
\hline $\begin{array}{l}\text { Chronic pain as primary } \\
\text { illness (598) }\end{array}$ & $39(6.5 \%)$ & $74(12.4 \%)$ & $131(21.9 \%)$ & $196(32.8 \%)$ & 107 (17.9\%) & $51(8.5 \%)$ \\
\hline $\begin{array}{l}\text { Arthritis as primary } \\
\text { illness (188) }\end{array}$ & $10(5.3 \%)$ & $31(16.5 \%)$ & $36(19.2 \%)$ & $65(34.6 \%)$ & $38(20.2 \%)$ & $8(4.3 \%)$ \\
\hline 3 Yes $(343)^{a}$ & $10(2.9 \%)$ & $54(15.7 \%)$ & $87(25.4 \%)$ & $114(33.2 \%)$ & $53(15.5 \%)$ & $25(7.3 \%)$ \\
\hline 2 Yes $(102)^{b}$ & $4(3.9 \%)$ & $13(12.8 \%)$ & $30(29.4 \%)$ & $28(27.5 \%)$ & $21(20.6 \%)$ & $6(5.9 \%)$ \\
\hline $3+2$ Yes (445) & $14(3.2 \%)$ & $67(15.1 \%)$ & $117(26.3 \%)$ & $142(31.9 \%)$ & $74(16.6 \%)$ & $31(7.0 \%)$ \\
\hline \multicolumn{7}{|c|}{ Employment status } \\
\hline & $\begin{array}{l}\text { Employed, working } \\
\text { full-time }\end{array}$ & $\begin{array}{l}\text { Employed, working } \\
\text { part-time }\end{array}$ & Retired & $\begin{array}{l}\text { Not employed, } \\
\text { looking for work }\end{array}$ & $\begin{array}{l}\text { Not employed, } \\
\text { not looking for } \\
\text { work }\end{array}$ & $\begin{array}{l}\text { Disabled, not } \\
\text { able to work }\end{array}$ \\
\hline All patients (2032) & $1045(51.4 \%)$ & $231(11.4 \%)$ & $120(5.9 \%)$ & $164(8.1 \%)$ & 88 (4.3\%) & 384 (18.9\%) \\
\hline $\begin{array}{l}\text { Headache as primary } \\
\text { symptom (505) }\end{array}$ & 268 (53.1\%) & 50 (9.9\%) & $10(2 \%)$ & $36(7.1 \%)$ & 30 (5.9\%) & $111(22 \%)$ \\
\hline $\begin{array}{l}\text { Headache as primary } \\
\text { illness (75) }\end{array}$ & $56(74.7 \%)$ & $4(5.3 \%)$ & $1(1.3 \%)$ & $1(1.3 \%)$ & $5(6.7 \%)$ & $8(10.7 \%)$ \\
\hline $\begin{array}{l}\text { Chronic pain as primary } \\
\text { illness (598) }\end{array}$ & 278 (46.5\%) & $64(10.7 \%)$ & 33 (5.5\%) & $30(5 \%)$ & $24(4 \%)$ & 169 (28.3\%) \\
\hline $\begin{array}{l}\text { Arthritis as primary } \\
\text { illness (188) }\end{array}$ & $94(50 \%)$ & $18(9.6 \%)$ & $38(20.2 \%)$ & $13(6.9 \%)$ & $4(2.1 \%)$ & $21(11.2 \%)$ \\
\hline 3 Yes $(343)^{a}$ & $172(50.2 \%)$ & 31 (9\%) & $6(1.8 \%)$ & $24(7 \%)$ & $21(6.1 \%)$ & $89(26 \%)$ \\
\hline 2 Yes $(102)^{b}$ & $59(57.8 \%)$ & $12(11.8 \%)$ & $2(2 \%)$ & $9(8.8 \%)$ & $3(2.9 \%)$ & $17(16.7 \%)$ \\
\hline $3+2$ Yes (445) & 231 (51.9\%) & $43(9.7 \%)$ & $8(1.8 \%)$ & $33(7.4 \%)$ & $24(5.4 \%)$ & $106(23.8 \%)$ \\
\hline
\end{tabular}

${ }^{2} 3$ "Yes" responses $=97 \%$ probability of migraine

${ }^{b_{2}}$ "Yes" responses $=93 \%$ probability of migraine

in inflammatory and pain processing, and plays regulatory physiological roles across virtually every organ system [19, 46, 71-74]. The endocannabinoid system interacts within its own pathways, as well as within major endogenous pain pathways, including inflammatory, endorphin/enkephalin, vanilloid/transient receptor potential cation channel subfamily V (TRPV), subfamily M (TRPM), subfamily A (TRPA), and nuclear receptors/transcription factors called the peroxisome proliferator-activated receptors (PPAR) [75].

The activities of the endocannabinoid system are based on the pre-synaptic $G$ protein-coupled cannabinoid 1 (CB1) and 2 (CB2) receptors [76]. There is also a presumed third cannabinoid receptor, $G$ protein-coupled receptor 55 (GPR55), termed CB3 [77]. The primary endogenous cannabinoid receptor ligands (endogenous cannabinoids, or endocannabinoids) are arachidonic acid derivatives, and they work via retrograde signaling receptor activation. The primary mediator of endocannabinoid signaling is $\mathrm{N}$-arachidonoylethanolamine (anandamide, or AEA), and 2-arachidonoylglycerol (2-AG) is another primary endocannabinoid [71, 78-80]. Cannabis-based phytocannabinoids, as well as inherent endocannabinoids interact at the $\mathrm{CB} 1$ and $\mathrm{CB} 2$ receptors with variable affinities and actions [81-83].

The CB1 receptor is the most abundant G proteincoupled receptor in the brain and one of the most abundant in both the peripheral and central nervous system [81]. CB1 receptors are expressed primarily on presynaptic peripheral and central nerve terminals, and are found extensively through the anatomical pain pathways as well as many other neurological central and peripheral 
Table 11 Medicinal cannabis reported as a substitute for prescription drugs among various pain syndromes and "Yes" responses on ID Migraine ${ }^{\mathrm{TM}}$ questionnaire

\begin{tabular}{|c|c|c|c|c|c|c|c|}
\hline \multicolumn{8}{|c|}{ Prescription drugs replaced } \\
\hline & Yes & Opiates, opioids & NSAIDs, Analgesics & Triptans/Ergots & $\begin{array}{l}\text { Anti-depressant, } \\
\text { Anti-anxiety }\end{array}$ & Anti-convulsant & $\begin{array}{l}\text { Muscle } \\
\text { Relaxers }\end{array}$ \\
\hline $\begin{array}{l}\text { Headache as primary } \\
\text { symptom (505) }\end{array}$ & $272(53.9 \%)$ & $118(43.4 \%)$ & $57(21 \%)$ & $22(8.1 \%) / 1(0.4 \%)$ & $106(39 \%)$ & $21(7.7 \%)$ & $19(7 \%)$ \\
\hline $\begin{array}{l}\text { Headache as primary } \\
\text { illness (75) }\end{array}$ & $36(48 \%)$ & 19 (52.8\%) & $11(30.6 \%)$ & $14(38.9 \%)$ & $5(13.9 \%)$ & $1(2.8 \%)$ & $4(11.1 \%)$ \\
\hline $\begin{array}{l}\text { Chronic pain as primary } \\
\text { illness (598) }\end{array}$ & $316(52.8 \%)$ & $230(72.8 \%)$ & $64(20.3 \%)$ & $3(1 \%)$ & $74(23.4 \%)$ & $41(13 \%)$ & $30(9.5 \%)$ \\
\hline $\begin{array}{l}\text { Arthritis as primary } \\
\text { illness (188) }\end{array}$ & $90(47.9 \%)$ & $48(53.3 \%)$ & $37(41.1 \%)$ & $2(2.2 \%)$ & $15(16.7 \%)$ & $5(5.6 \%)$ & $7(7.8 \%)$ \\
\hline 3 Yes $(343)^{a}$ & $204(59.5 \%)$ & $92(45.1 \%)$ & $45(22.1 \%)$ & $20(9.8 \%) / 1(0.5 \%)$ & $84(41 \%)$ & $13(6 \%)$ & $15(7.4 \%)$ \\
\hline 2 Yes $(102)^{b}$ & $42(41.2 \%)$ & 17 (40.5\%) & $6(14.3 \%)$ & $2(4.8 \%)$ & 15 (35.7\%) & $6(14.3 \%)$ & $4(9.5 \%)$ \\
\hline $3+2$ Yes (445) & $246(55.3 \%)$ & $109(44.3 \%)$ & $51(20.7 \%)$ & $22(8.9 \%) / 1(0.4 \%)$ & 99 (40.2\%) & $19(7.7 \%)$ & $19(7.7 \%)$ \\
\hline
\end{tabular}

a "Yes" responses $=97 \%$ probability of migraine

${ }^{b} 2$ "Yes" responses $=93 \%$ probability of migraine

locations [19, 84-87]. CB1 receptors are associated with the "high" felt with some cannabis strains, activated by THC. Activation leads to hyperpolarization of the pre-synaptic terminal, closing of calcium channels with subsequent inhibition of released stored inhibitory and excitatory neurotransmitters, including glutamate, 5-hydroxytryptamine (5-HT; serotonin), gamma-aminobutyric acid (GABA), noradrenaline, dopamine, acetylcholine, D-aspartate, and cholecystokinin at inhibitory and excitatory synapses $[19,71,73,80,86$, 88-90], and can modulate pain pathways involving opioid, serotonin, and N-methyl-d-aspartate (NMDA) receptors through other indirect mechanisms [91].

The CB2 receptors are located primarily in the peripheral tissues and immune cells where they influence the release of cytokines, chemokines, and cell migration including neutrophils and macrophages, but do have some presence in the central nervous system [18, 86, 92-95], and may also contribute to pain relief by dopamine release modulation [96, 97].

Over 540 phytochemicals have been described in cannabis [98], 18 different chemical classes, and more than 100 different phytocannabinoids, although some are breakdown products $[99,100]$. THC and CBD have been the most researched and are considered the major cannabinoids. There are many additional cannabinoids referred to as minor cannabinoids. The quantities of major and minor cannabinoids are widely variable between different types of cannabis strains. There is evidence for analgesic and anti-inflammatory effects in many of the cannabinoids, and this publication will focus primarily on these properties for the cannabinoids assessed in this study. However, a more extensive discussion and a comprehensive review of other medicinal properties of these, as well as many other cannabinoids, has been summarized and is available
[28]. The cannabinoids analyzed in this study were limited to THC, THCA, CBD, and CBDA.

THC is one of the most researched cannabinoids, and the cause of the psychoactive side effects of cannabis, suspected from modulation of glutamate and GABA systems $[18,83,101-103]$. It is a partial agonist at CB1 greater than CB2 receptors, which are its primary mechanisms of action. However, other mechanisms of action reflect its activity as an agonist at the PPAR- $\gamma$ and TRPA1 receptors [83], a 5HT3A antagonist, a glycine receptor activation enhancer via allosteric modification, reduces elevated intracellular calcium levels from TRPM8 activity (cold and menthol receptor 1 (CMR1)), elevates calcium levels by TRPA1 or TRPV2, and stimulates G Protein Receptor 18 and other nuclear receptors [104-113]. It reduces NMDA responses by 30-40\% [114-116], blocks capsaicin-induced hyperalgesia [117], inhibits CGRP activity [118], increases cerebral $5 \mathrm{HT}$ production, decreases $5 \mathrm{HT}$ reuptake, and inhibits $5 \mathrm{HT}$ release from platelets, all of which may influence trigeminovascular migraine circuitry [1, 68, 69, 119]. THC enhances analgesia from kappa opioid receptor agonist medications [120-123], stimulates production of beta-endorphin and increases proenkephalin mRNA levels in brainstem regions involved in pain processing [124-126], and intraventricular and intrathecal administration of THC produces analgesia similar to opioids [127].

THC is 20 times more anti-inflammatory than aspirin, twice as anti-inflammatory as hydrocortisone [128], and has well documented analgesic and anti-inflammatory benefits including arthritic and inflammatory conditions [83, 114, 127, 129-156]. There have been many positive studies across various chronic pain syndromes, showing benefit of THC in trials with smoked or vaporized cannabis comparing between different doses of THC, with 
benefit often noted at higher percentages [28, 47, 157169]. However, compositions of other cannabinoids including CBD, minor cannabinoids, and other important compounds such as terpenes were not assessed in most of these trials. Given the entourage effects of cannabis $[100,170]$, where cannabinoids and terpenes influence activity of one another, resulting in strainspecific characteristics, effects and responses, it is often unclear if these studies showing positive (or negative) effects of cannabis are due to the THC alone, or due to synergy between undefined compositions of other cannabinoids and terpenes.

There have been a multitude of studies confirming benefit in various chronic pain syndromes with an oralmucosal spray called Nabiximols (Sativex) [171-196], approved in 30 countries for various neurological symptoms. This is a tincture of cannabis made from cannabis plants [197]. Each spray delivers a standardized dose of $2.7 \mathrm{mg}$ THC and $2.5 \mathrm{mg}$ CBD, along with additional cannabinoids, flavonoids, and terpenes in unmeasured small amounts. Despite the standardized THC:CBD ratio, the actual concentrations of terpenes and other compounds are unknown. This again creates uncertainty as to what components are providing most of the benefit, although entourage effects are again suspected. There was also a study comparing between three varieties of this spray; 1:1 THC:CBD vs. THC alone vs. CBD alone and the sprays that contained THC showed the most pain benefit, over CBD alone [179]. Other cannabis extract studies of only THC and CBD in varying doses also showed pain benefit, although these did not evaluate each cannabinoid individually [187, 198].

The strong anti-emetic benefits of THC have also been well documented in adults [26, 83, 129, 130, 199-238] and children [235, 239-241], and migraine associated nausea and vomiting would certainly be another benefit of THC. In fact, the FDA has approved two synthetic forms of THC in the treatment of chemotherapy related nausea and vomiting; Dronabinol [242] and Nabilone [243]. Notably, these synthetic THC medications have also shown analgesic effects [55, 57, 62, 188, 244-256].

Besides THC, CBD is the other major cannabinoid. It has gained a lot of attention over the past several years due to its lack of any psychoactivity, as opposed to THC. In November 2017, The World Health Organization announced that in humans, CBD exhibits no evidence for abuse or dependence potential, and there is no evidence of public health related problems associated with the use of pure CBD [257]. In January 2018, the World Anti-Doping Agency (WADA) removed CBD from their prohibited list, no longer banning use by athletes [258]. CBD has powerful analgesic and anti-inflammatory effects [23, 83, 114, 129-131, 137-140, 149, 259-281] mediated by both cyclooxygenase and lipoxygenase inhibition. Its anti-inflammatory effect is several hundred times more potent than aspirin [128, 282], although to date, there have been no clinical studies evaluating pure CBD in headache or chronic pain disorders. CBD has much lower affinity for $\mathrm{CB} 1$ or $\mathrm{CB} 2$ receptors, and acts as an antagonist of $\mathrm{CB} 1$ and $\mathrm{CB} 2$ agonists such as THC [276]. At low concentrations, its antagonism of $\mathrm{CB} 1$ underlies its neutralizing effects on the CB1 agonist THC side effects such as anxiety, tachycardia, and sedation [283-288]. CBD appears to attenuate some of these negative side effects of THC when the CBD:THC ratio is at least 8:1 $( \pm 11.1)$, but may potentiate some of the THC side effects when the CBD:THC ratio is around $2: 1( \pm 1.4)[286,288]$. It is also an inverse agonist at the CB2 receptor, which may contribute to its antiinflammatory effects [276].

CBD also interacts with a multitude of ion channels, enzymes, and other receptors $[18,83,129,130,225,259]$. It acts as a TRPV1 agonist, similar to capsaicin, although without the noxious sides effects, and also inhibits AEA uptake and metabolism [108-110, 289, 290]. It acts as a positive allosteric modulator at $\alpha 1$ and $\alpha 1 \beta$ glycine receptors [291], suggested to play a role in chronic pain after inflammation or nerve injury since glycine acts as an inhibitory postsynaptic neurotransmitter in the dorsal horn of the spinal cord. CBD acts as a $\mu$ opioid receptor ligand and a positive allosteric modulator at $\mu$ and $\delta$ opioid receptors suggesting that it may enhance opiate effects [83]. Additional mechanisms of action suggested to reflect its anti-inflammatory and analgesic effects, as well as other medicinal benefits, include TRPA1 agonist, TRPV1 agonist, TRPM8 antagonist [108-110], TRPV2 agonist in which it may mediate CGRP release from dorsal root ganglion neurons [292], T-type calcium ${ }^{2+}$ channel inhibitor [293], suppression of tryptophan degradation (precursor to $5 \mathrm{HT}$ ) [294], phospholipase A2 modulator [295], 5-HT1A agonist [83, 296], regulator of intracellular calcium ${ }^{2+}[297,298]$, fatty acid amide hydrolase (FAAH; breaks down AEA) inhibition [290], GPR55 antagonist [77], adenosine uptake competitive inhibitor [299], PPAR $\gamma$ agonist [300], 5-lipoxygenase and 15-lipoxygenase inhibitors [301], and antagonism of the abnormal-CBD receptor [83, 302].

Cannabinoid acids are the precursors to the cannabinoids in raw and live cannabis, and have no psychotropic qualities. They are decarboxylated by heat, UV exposure, and prolonged storage to form the active cannabinoids, although heat such as from smoking or vaporizing is the primary conversion factor. The two cannabinoid acids assessed in this study were THCA, which converts to THC, and CBDA, which converts to CBD.

THCA is a TRPA1 partial agonist [108], and TRPM8 antagonist [108] which may underlie a potential role in analgesia, and has been shown to have anti-inflammatory [140] and anti-nausea properties [303]. CBDA is often 
obtained through consumption of raw cannabis juice. It is a TRPA1 agonist [108], TRPV1 agonist [290], and TRPM8 antagonist [108] which may also reflect its potential as an analgesic. It is also anti-inflammatory $[130,140,304]$ via selective COX2 inhibition, and has anti-nausea properties [237, 305].

The terpenes, or terpenoids, form the largest group of phytochemicals [99], and account for some pharmacological properties of cannabis, as well as many medicinal herbs, plants and essential oils. They are the source of flavors, aromas, and other characteristics that help differentiate cannabis strains. The terms terpenes and terpenoids are often used interchangeably in the literature, although technically, terpenes are basic hydrocarbons, while terpenoids contain extra functional groups of a wide range of chemical elements. Cannabis contains up to 200 different terpenes [100], and they are generally classified as primary and secondary terpenes, based on how frequent they occur in cannabis. They are lipophilic with wide ranging mechanisms of action sites including neurotransmitter receptors, G-protein receptors, muscle and neuronal ion channels, enzymes, cell membranes, and second messenger systems [100, 306, 307]. The terpenes work synergistically with the cannabinoids for a variety of therapeutic effects, and this phenomenon is known as the cannabis entourage effects [100, 170]. They have shown many medicinal benefits, including anti-inflammatory and analgesic properties [308]. This publication will focus primarily on the antiinflammatory and analgesic evidence for the terpenes analyzed in this study, although a more extensive discussion and a comprehensive review of other medicinal properties of these, as well as many other terpenes has been summarized and is available [28]. The majority of this data comes from preclinical studies involving animal models or in vitro studies, and some of the reported benefits attributed to individual terpenes come from studies evaluating whole essential oils or plants in which the specified terpene may be a predominant constituent. However, therapeutic contribution from some of the other terpenes in some of these studies cannot be excluded. The terpenes analyzed in this study were limited to $\alpha$-pinene, $\beta$-myrcene, D-limonene, linalool, $\beta$ caryophyllene, humulene, trans-nerolidol, and bisabolol.

Alpha-pinene ( $\alpha$-pinene) is the most commonly occurring terpene in nature [309], and accounts for the aroma of fresh sage, pine needles, and conifers, but is produced by many herbs such as basil, parsley, and dill as well. It has anti-inflammatory effects in human chondrocytes, suggesting anti-osteoarthritic activity [310, 311], antiinflammatory effects by PGE-1 [312], and anti-nociception properties [313].

Beta-myrcene ( $\beta$-myrcene), or myrcene, is common in lemongrass, basil, bay leaves, wild thyme, parsley, hops, and tropical fruits such as mango. It has potent anti-inflammatory, analgesic, and anxiolytic properties [314-316], and has benefit in muscle relaxation [317], and prominent sedation/hypnotic, helpful in sleep [317, 318]. Its analgesic effects were antagonized by naloxone suggesting an opioid-mediated mechanism $[315,316]$. Its significant anti-inflammatory effects [319] occur via prostaglandin E2 [315] and it has anti-catabolic effects in human chondrocytes suggesting anti-osteoarthritic activity and the ability to halt or slow down cartilage destruction and osteoarthritis progression [320].

D-limonene (limonene) is prominent in the rinds of citrus fruits, and the second most commonly occurring terpene in nature [309]. It has analgesic [321], antiinflammatory [320, 322-325], and antidepressant effects $[321,326]$. It contributes to muscle relaxation and sleep [317], and is a powerful anxiolytic [327-330], which extended anxiolytic benefit to patients with chronic myeloid leukemia (CML) [331]. It increases the metabolic turnover of dopamine in the hippocampus and serotonin in the prefrontal cortex and striatum, suggesting that anxiolytic and antidepressant-like effects may occur by the suppression of dopamine activity related to enhanced serotonergic neurons, especially via 5-HT1A [332].

Linalool is found in flowers and spices including citrus, lavender, rosewood, birch trees, and coriander. It exhibits anti-inflammatory and analgesic activity [333-335] as well as anti-nociception via activation of opioidergic and cholinergic systems [333], anticonvulsant via antiglutamatergic and GABA neurotransmitter systems [336-340], anti-anxiety/stress [341-344], sedation [343, 345-347], and anti-insomnia properties [100]. Its local anesthetic effects [348] were equivalent to procaine and menthol [349], and analgesic effects have been attributed to adenosine $\mathrm{A}_{2 \mathrm{~A}}$ activity [350] and ionotropic glutamate receptors including AMPA, NMDA and kainate [351]. Morphine opioid usage in gastric banding surgical patients was significantly decreased following lavender inhalation vs. placebo, and this was attributed to the linalool concentration [352].

Beta-caryophyllene ( $\beta$-caryophyllene) is found in spices and plants including cloves, cinnamon, black pepper, hops, rosemary, oregano, and basil. It has analgesic effects in inflammatory and neuropathic pain [353], and has potent anti-inflammatory effects [354-357], with local anesthetic properties [358]. Anti-inflammatory effects appear to occur via PGE-1 [359], with similar efficacy as indomethacin and etodolac [360,361], and comparable to phenylbutazone $[359,360]$. $\beta$-caryophyllene is a selective cannabinoid receptor 2 (CB2) agonist [362-364]. CB2 receptors have been implicated in anxiety and depression, and $\beta$-caryophyllene has shown anxiolytic and antidepressant effects [365]. 
Humulene ( $\alpha$-caryophyllene) is an isomer of $\beta$ caryophyllene and plays a role in many of the distinguishing characteristics between different cannabis strains. It is found in herbs and spices such as clove, basil, hops, sage, spearmint and ginseng, in addition to some vegetables and fruits. It has strong anti-inflammatory properties comparable to dexamethasone systemically, topically, and in allergic airway inflammation [354-356, 366, 367], as well as anti-nociceptive and analgesic properties [367].

Nerolidol (trans-nerolidol) is found in many herbs and spices including lavender, lemon grass, ginger, jasmine, tea tree, oranges, and present in orange and other citrus peels. It has anti-insomnia and sedative properties [368].

Alpha-bisabolol ( $\alpha$-bisabolol, bisabolol, levomenol) is produced by some flowers used in making tea, such as the chamomile flower. It has anti-inflammatory effects in the skin [369], as well as anti-nociceptive properties [370].

Cannabis sativa strains are generally described by patients as uplifting, energetic, creative, euphoria, spacey, cerebrally-focused effects, and better for day use, while Cannabis indica strains are typically described as calming, relaxing, sedative, full body effects such as "body buzz", and better for night use. Research suggests these effects are not likely due purely to CBD:THC ratios, as there are no significant differences in CBD:THC ratios between Sativa and Indica strains. Rather these different subjective effects are likely due to varying ratios of major cannabinoids as well as minor cannabinoids, terpenes and probably additional phytochemicals [100, 371-374]. High CBD strains are Sativa or Indica strains that have been crossed with high CBD hemp strains (1:1 CBD: THC up to approximately 5:1 CBD:THC), while pure CBD strains (ratios of > 10:1 CBD:THC, which can be up to approximately 50:1 CBD:THC) are considered hemp strains. Most strains utilized today are Hybrids designed with standardized ratios of CBD, THC, other cannabinoids, and other compounds such as terpenes and flavonoids, targeting specific symptoms, responses, and end user effects.

Although not of statistical significance, there were some pattern use trends noted. The majority of patients across all pain groups including the positive ID Migraine $^{\mathrm{rm}}$, headache as primary symptom, chronic pain, and arthritis groups all preferred Hybrid cannabis strains followed by Indica, Sativa, and higher CBD strains (1:1 CBD:THC, 3:1 CBD:THC) when patients with headache as primary symptom were included. However, when these patients were excluded, the arthritis group preferred Indica strains. When comparing headache and migraine to non-headache groups, Indica strains were preferred in the insomnia/sleep disorders group, Sativa strains in the mental health condition/PTSD group, and Hybrid strains were still preferred in the gastrointestinal disorder/Crohn's Disease group. Perhaps the headache, chronic pain, and gastrointestinal disorder/Crohn's groups preferred similar Hybrid strains due to underlying inflammatory pathophysiology. The positive ID Migraine $^{\mathrm{Ts}}$ and headache as primary symptom patients most commonly preferred the "OG Shark" Hybrid strain specifically, although this pattern was also noted in the chronic pain and arthritis groups, so was not unique to headache and migraine. This is a high THC/THCA, low $\mathrm{CBD} / \mathrm{CBDA}$ strain with $\beta$-caryophyllene followed by $\beta$ myrcene as the predominant terpenes. This could reflect the potent analgesic, anti-inflammatory, and anti-emetic properties of $\mathrm{THC}$, along with documented antiinflammatory and analgesic properties of $\beta$-caryophyllene and $\beta$-myrcene. Given the prominent features of pain with nausea and vomiting in migraine headache, the fact that headache and migraine patients preferred a strain such as this, with its associated cannabinoid and terpene profile, would make sense given the known therapeutic effects of this cannabinoid and these terpenes. Furthermore, there were additional terpenes present in this strain of lower percentages, some of which also have analgesic and antiinflammatory properties.

Substituting cannabis for alcohol, illicit drugs and/ or prescription medications has been commonly observed in cross sectional surveys, suggesting a harm reduction role in the use of these substances, as well as implications for abstinence-based substance use treatment strategies [375-377]. The "opioid-sparing effect" of cannabinoids has been well described with extensive supporting evidence showing that combining cannabis with opiates decreases opiate dose requirements [166, 378]. CB1 receptors are 10 times more concentrated then mu-opioid receptors in the brain, and cannabinoid receptors co-localize with opioid receptors in many regions involved in pain pathways. This is suspected to contribute to synergistic augmentation of the analgesic opioid effects and decreased opioid dose requirements [8, 122-125, 166, 379-384], and studies have shown cannabis use did not affect blood levels of oxycodone or morphine [8, 166]. Cannabinoid receptor agonists increase endogenous opioid peptide release, and chronic THC use increases endogenous opioid precursor gene expression in supraspinal and spinal structures involved in pain perception [119, 126, 166, 379].

The synergistic effect of concomitant cannabis/cannabinoids and opioids in lowering both pain and opioid dose requirements without affecting serum opioid levels has been demonstrated prospectively [166]. A large meta-analysis showed that 17 of 19 pre-clinical studies provided good evidence of these synergistic effects from opioid and cannabinoid co-administration and that the median effective dose (ED50) of morphine administered with THC is 3.6 times lower than the ED50 of morphine 
alone, while the ED50 for codeine administered with THC was 9.5 times lower than the ED50 of codeine alone [378]. The combination of cannabis/cannabinoids and opioids appears to allow for opioid treatment at lower doses with fewer side effects, allowing easier detoxification and weaning due to lessening of tolerance and withdrawal from opiates, and rekindling of opiate analgesia after prior dosages have worn off [124]. Some pain specialists have suggested the use of medicinal cannabis treatment in addition to or in replacement of opiate treatments to help reduce overdose mortality and morbidity associated with opiate use [385]. Prospective studies have shown that chronic pain patients who use cannabis have improved pain and functional outcomes, and a significant reduction in opioid use [386], and medical cannabis use was associated with decreased opiate use, improvement in quality of life, and better side effect profile in a retrospective cross-sectional survey of chronic pain patients [387].

Notably, the most common prescription medications replaced by medicinal cannabis in this study were opiates/opioids in a large percentage within every pain group, up to $72.8 \%$ of patients in the chronic pain as primary illness group. Given the opioid epidemic, particularly in the United States, cannabis has been discussed as an option that may help in the opioid/opiate detoxification and weaning process and perhaps assist in combating the epidemic of opioid related death [377, 385, 388-390]. States with medicinal cannabis laws have been shown to have a $24.8 \%$ decreased annual opioid overdose mortality rate compared with states without medicinal cannabis laws. The association between medicinal cannabis law implementation and decrease in annual opioid overdose mortality strengthened over time to a decrease of $33.7 \%$ by year 5 [391].

The synergistic interactions between the phytocannabinoids, terpenes and other cannabis compounds resulting in various therapeutic benefits and responses have been termed the cannabis entourage effects [100, 170]. This synergy between the cannabinoids, terpenes, and other compounds leads to variable benefits, user effects, and strain characteristics. In addition, synergistic interactions between cannabis and opioid pathways may be a promising new weapon in the battle of the opioid epidemic. Further study is needed to determine optimal combinations for specific synergies and composition ratios of the cannabis constituents to best target different symptoms and diseases. Medicinal cannabis production has become a very sterile, scientific, standardized production process, and an emerging new industry. Similar to the broad category of anticonvulsants with many varieties targeting variable neurochemical pathways and channels with different responses and side effects, cannabis should also be thought of a broad category of medicine, of which further therapeutic delineations and disease targeting differentiations between strains is necessary.

There are multiple limitations to this study beginning with its survey design and inherent limitations. Many of the patients who reported headache as a primary symptom for which they were treating with medicinal cannabis, had also reported other diseases or symptoms that they were using medicinal cannabis for. So, some of the answers provided may not have been specific for only headache treatment, but potentially other symptoms or a combination of symptoms including headache. This could also influence reported preferred strains being used since some strains are used more commonly for some symptoms, while other strains may be used for other symptoms. There may be some inaccuracy of patient numbers within the different pain groups of chronic pain, arthritis, and headache. For example, some patients who reported chronic pain as the primary illness for which they were using medicinal cannabis did not specify their type of chronic pain further. It is unknown if some of these patients may have been treating chronic pain of arthritis or headache types, but reporting it as chronic pain, and therefore some of these patients may have been more accurately listed in a different more specific category. Variability in patients' cannabis knowledge could potentially influence self-reporting accuracy. When documenting the preferred cannabis types and strains within each of the pain and non-pain groups, many patients did not provide an answer for their preferred type or strain. If a preferred cannabis type was not provided, but a preferred strain was provided, then their preferred type was presumed to correlate to their reported preferred strain, and counted as such. In addition, reported preferred cannabis types and strains sometimes did not correlate (reported strain did not fall under the correct reported type). Therefore, the preferred cannabis types and strains listed within each category, and their inferred potential benefits, may be inaccurate based on this inconsistent reporting by some patients, and the validity of the preferred cannabis type and strain data requires prospective validation.

\section{Conclusions}

Chronic pain was the most common reason for use of medicinal cannabis, consistent with the statistics of most registries. Identifying differences in use patterns between migraine, headache, arthritis, and chronic pain syndromes may be helpful in optimizing crossbred cannabis strains, synergistic biochemical profiles, or dosing differences between these pain subsets. The majority of patients treating headache with medicinal cannabis were positive for migraine (88\%) according to the ID 


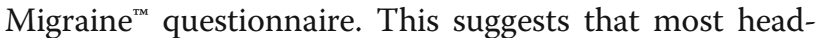
aches being treated with medicinal cannabis were likely of migrainous pathophysiology.

Hybrid cannabis strains were preferred across most pain groups. "OG Shark", a high THC/THCA, low CBD/ CBDA strain with $\beta$-caryophyllene followed by $\beta$ myrcene as the predominant terpenes, was the most preferred strain in the positive ID Migraine ${ }^{\mathrm{rm}}$ and headache as primary symptom groups. This could reflect the potent analgesic, anti-inflammatory, and anti-emetic properties of THC, along with documented anti-inflammatory and analgesic properties of $\beta$ caryophyllene and $\beta$-myrcene. Since migraines also involve nausea and vomiting, the potent antiemetic properties of THC may be a reason for this preference. Vaporizing or joint use were the primary methods of use across all groups, including migraine and headache, likely reflecting the need for a quick acting inhaled or non-orally ingested therapy in migraine attacks before severe pain and nausea/vomiting become prominent.

Most patients in the pain groups reported replacing prescription medications with medicinal cannabis, the most common of which were opiates/opioids across all pain groups. This is notable given the well-described "opioid-sparing effect" of cannabinoids and growing abundance of literature suggesting that cannabis may help in weaning from these medications and perhaps providing a means of combating the opioid epidemic. There are several limitations to the data in this study, and these results require further confirmation with more sophisticated prospective study methods. However, these results may provide early insight and a framework for direction into optimizing crossbred cannabis strains, synergistic biochemical profiles, dosing, and patterns of use that may be of clinical benefit in the treatment of headache and migraine, as well as other chronic pain syndromes.

\footnotetext{
Abbreviations

2-AG: 2-arachidonoylglycerol; 5-HT: 5-hydroxytryptamine (serotonin); AEA: Narachidonoylethanolamine (anandamide); AMPA: a-amino-3-hydroxy-5methyl-4-isoxazolepropionic acid; CB1: Cannabinoid 1 receptor; CB2: Cannabinoid 2 receptor; CB3: Cannabinoid 3 receptor; CBD: Cannabidiol; CBDA: Cannabidiolic acid; CGRP: Calcitonin gene related peptide; CML: Chronic myeloid leukemia; CMR1: Cold and menthol receptor 1; COX2: Cyclooxygenase-2; ED50: Median effective dose; FAAH: Fatty acid amide hydrolase; FDA: Federal drug administration; GABA: Gammaaminobutyric acid; GPR55: G protein-coupled receptor 55; NMDA: N-methyld-aspartate; NNT: Number needed to treat; NSAID: Non-steroidal antiinflammatory drug; PGE-1: Prostaglandin E1; PPAR: Peroxisome proliferatoractivated receptors; PTSD: Post-Traumatic Stress Disorder; THC: $\triangle 9$ Tetrahydrocannabinol; THCA: Tetrahydrocannabinolic acid; TRPA: Transient receptor potential cation channel, subfamily A; TRPM: Transient receptor potential cation channel, subfamily M; TRPV: Transient receptor potential cation channel subfamily V; WADA: World Anti-Doping Agency
}

\section{Funding}

A $\$ 10$ patient account credit was offered to each patient completing the online survey, funded by Tilray $(\$ 20,000$ budget).

\section{Availability of data and materials}

Data gathering was done on REDCap, a HIPAA and PIPEDA compliant electronic data capture system, and is present on private locked files.

\section{Authors' contributions}

EB is the primary author of the manuscript, helped incorporate the ID Migraine ${ }^{T M}$ questionnaire into the survey, and analyzed/organized the survey data. PL designed the survey, coordinated its administration and data collection, and assisted in writing of the manuscript. JE conducted the biochemical analysis of cannabis strain cannabinoid and terpene compositions, and reviewed the manuscript. $\mathrm{OH}$ conducted the statistical analysis of the data and assisted with writing of the correlating statistical analysis data in the manuscript. All authors read and approved the final manuscript.

\section{Ethics approval and consent to participate}

The survey was ethics approved by the Investigational Review Board (IRB) Services of both Tilray and Cleveland Clinic.

\section{Competing interests}

PL: Vice-President of Patient Research and Access for Tilray, ownership interest (stocks, stock options, or other ownership interest excluding diversified mutual funds), salary.

JE: Vice-President and Chief Science Officer for Tilray, ownership interest (stocks, stock options, or other ownership interest excluding diversified mutual funds), salary.

\section{Publisher's Note}

Springer Nature remains neutral with regard to jurisdictional claims in published maps and institutional affiliations.

\section{Author details}

${ }^{1}$ Center for Neurological Restoration - Headache and Chronic Pain Medicine, Department of Neurology, Cleveland Clinic Neurological Institute, 10524 Euclid Avenue, C21, Cleveland, OH 44195, USA. ${ }^{2}$ Tilray, 1100 Maughan Rd, Nanaimo, BC V9X 1J2, Canada. ${ }^{3}$ Social Dimensions of Health, University of Victoria, 3800 Finnerty Rd, Victoria, BC V8P 5C2, Canada. ${ }^{4}$ Canadian Institute for Substance Use Research, 2300 McKenzie Ave, Victoria, BC V8N 5M8, Canada. ${ }^{5}$ Section of Biostatistics, Department of Quantitative Health Sciences, Cleveland Clinic Lerner Research Institute, 9500 Euclid Avenue, JJN3,

Cleveland, $\mathrm{OH}$ 44195, USA.

Received: 13 April 2018 Accepted: 4 May 2018

Published online: 24 May 2018

\section{References}

1. Russo E (1998) Cannabis for migraine treatment: the once and future prescription? An historical and scientific review. Pain 76:3-8

2. Baron EP (2015) Comprehensive review of medicinal marijuana, cannabinoids, and therapeutic implications in medicine and headache: what a long strange trip it's been .... Headache 55:885-916

3. Brunner TF (1973) Marijuana in ancient Greece and Rome? The literary evidence. Bull Hist Med 47:344-355

4. Kuddus M, Ginawi IAM, Al-Hazimi A (2013) Cannabis sativa: an ancient wild edible plant of India. Emir J Food Agric 25:736-745

5. Mikuriya TH (1969) Marijuana in medicine: past, present and future. Calif Med 110:34-40

6. Mikuriya TH (1973) Marijuana: medical papers 1839-1972. Medi-Comp Press, Oakland

7. O'Shaughnessy WB (1843) On the preparations of the Indian hemp, or gunjah (cannabis indica): their effects on the animal system in health, and their utility in the treatment of tetanus and other convulsive diseases. Prov Med J Retrosp Med Sci 5:363-369

8. McGeeney BE (2013) Cannabinoids and hallucinogens for headache. Headache 53:447-458

9. McGeeney BE (2012) Hallucinogens and cannabinoids for headache. Headache 52(Suppl 2):94-97

10. Clendinning J (1843) Observations on the medical properties of the cannabis sativa of India. Med Chir Trans 26:188-210

11. Greene R (1872) Cannabis Indica in the treatment of migraine. Practitioner 41:267-270 
12. Osler W, McCrae T (1915) The principles and practice of medicine. Appleton, New York

13. Mackenzie S (1887) Remarks on the value of Indian hemp in the treatment of a certain type of headache. Br Med J 1:97-98

14. Farlow JW (1889) On the use of belladonna and cannabis Indica by the rectum in gynecological practice. Boston Med Surg J 120:507-509

15. Reynolds JR (1890) On the therapeutic uses and toxic effects of cannabis Indica. Lancet 135:637-638

16. Fishbein M (1942) Migraine associated with menstruation. J Am Med Assoc 237:326

17. British Medical Association (1997) Therapeutic uses of Cannabis. Harwood Academic Publishers, Netherlands

18. Koppel BS, Brust JC, Fife T et al (2014) Systematic review: efficacy and safety of medical marijuana in selected neurologic disorders: report of the guideline development subcommittee of the American Academy of Neurology. Neurology 82:1556-1563

19. Aggarwal SK (2013) Cannabinergic pain medicine: a concise clinical primer and survey of randomized-controlled trial results. Clin J Pain 29:162-171

20. Lynch ME, Ware MA (2015) Cannabinoids for the treatment of chronic noncancer pain: an updated systematic review of randomized controlled trials. J Neurolmmune Pharmacol 10:293-301

21. Lynch ME, Campbell F (2011) Cannabinoids for treatment of chronic noncancer pain; a systematic review of randomized trials. Br J Clin Pharmacol 72:735-744

22. Whiting PF, Wolff RF, Deshpande $S$ et al (2015) Cannabinoids for medical use: a systematic review and meta-analysis. JAMA 313:2456-2473

23. Boychuk DG, Goddard G, Mauro G, Orellana MF (2015) The effectiveness of cannabinoids in the management of chronic nonmalignant neuropathic pain: a systematic review. J Oral Facial Pain Headache 29:7-14

24. Committee of the Health Effects of Marijuana (2017) An evidence review and research agenda. The health effects of cannabis and cannabinoids. The current state of evidence and recommendations for research. The National Academies Press, Washington, DC

25. Moulin D, Boulanger A, Clark AJ et al (2014) Pharmacological management of chronic neuropathic pain: revised consensus statement from the Canadian Pain Society. Pain Res Manag 19:328-335

26. Gurley RJ, Aranow R, Katz M (1998) Medicinal marijuana: a comprehensive review. J Psychoactive Drugs 30:137-147

27. Zuardi AW (2006) History of cannabis as a medicine: a review. Rev Bras Psiquiatr 28:153-157

28. Baron EP (2018) Medicinal properties of cannabinoids, terpenes and flavonoids in cannabis, and potential roles in migraine, headache, and pain: an update on current evidence and cannabis science. Headache In Press

29. Ilgen MA, Bohnert K, Kleinberg F et al (2013) Characteristics of adults seeking medical marijuana certification. Drug Alcohol Depend 132:654-659

30. Hazekamp A, Heerdink ER (2013) The prevalence and incidence of medicinal cannabis on prescription in the Netherlands. Eur J Clin Pharmacol 69:1575-1580

31. Medical Marijuana Registry Statistics. Colorado Department of Health and Environment. https://www.colorado.gov/pacific/cdphe/medicalmarijuana. Accessed 1 Dec 2017

32. Medical Cannabis Registry. Minnesota Department of Health. http://www. health.state.mn.us/topics/cannabis/registry.html. Accessed 1 Dec 2017

33. Medical cannabis patient registry program. Illinois Department of Public Health. http://www.dph.illinois.gov/topics-services/prevention-wellness/ medical-cannabis. Accessed 1 Dec 2017

34. Medical cannabis program. Hawaii Department of Health. http://health. hawaii.gov/medicalcannabis/. Accessed 1 Dec 2017

35. Oregon Medical Marijuana Program Statistics. Oregon Health Authority. http://www.oregon.gov/oha/PH/DISEASESCONDITIONS/CHRONICDISEASE/ MEDICALMARIJUANAPROGRAM/Pages/data.aspx. Accessed 1 Dec 2017

36. Medicinal Marijuana Program. State of New Jersey Department of Health. http://www.ni.gov/health/medicalmarijuana/. Accessed 1 Dec 2017

37. Medical Marijuana-Reports. Arizona Department of Health Services. http:// www.azdhs.gov/licensing/medical-marijuana/index.php\#reports. Accessed 1 Dec 2017

38. Medical Marijuana Patient Cardholder Registry Monthly Reports. Nevada Division of Public and Behavioral Health (DPBH). http://dpbh.nv.gov/Reg/ MM-Patient-Cardholder-Registry/MM_Patient_Cardholder_Registry_-_Home/. Accessed 1 Dec 2017
39. Michigan Medical Marihuana Act Statistical Reports. The Michigan Department of Licensing and Regulatory Affairs, Bureau of Medical Marihuana Regulation. http://www.michigan.gov/lara/0,4601,7-154-79571_ 82631-448788\%2D-00.html. Accessed 1 Dec 2017

40. el-Mallakh RS (1987) Marijuana and migraine. Headache 27:442-443

41. Grinspoon L, Bakalar JB (1993) Marihuana: the forbidden medicine. Yale University, New Haven

42. Volfe Z, Dvilansky A, Nathan I (1985) Cannabinoids block release of serotonin from platelets induced by plasma from migraine patients. Int J Clin Pharmacol Res 5:243-246

43. el-Mallakh RS (1989) Migraine headaches and drug abuse. South Med J 82:805

44. Schnelle M, Grotenhermen F, Reif M, Gorter RW (1999) Results of a standardized survey on the medical use of cannabis products in the German-speaking area. Forsch Komplementarmed 6(Suppl 3):28-36

45. Gorji A (2003) Pharmacological treatment of headache using traditional Persian medicine. Trends Pharmacol Sci 24:331-334

46. Greco R, Gasperi V, Maccarrone M, Tassorelli C (2010) The endocannabinoid system and migraine. Exp Neurol 224:85-91

47. Rhyne DN, Anderson SL, Gedde M, Borgelt LM (2016) Effects of medical marijuana on migraine headache frequency in an adult population. Pharmacotherapy 36:505-510

48. Donovan M (1845) On the physical and medicinal qualities of Indian hemp (Cannabis Indica); with observations on the best mode of administration, and cases illustrative of its powers. Dublin J Med Sci 26:368-461

49. Reynolds JR (1868) On some of the therapeutical uses of Indian hemp. Arch Med 2:154-160

50. Waring EJ (1874) Practical therapeutics. Lindsay \& Blakiston, Philadelphia

51. Russo E (2001) Hemp for headache: an in-depth historical and scientific review of cannabis in migraine treatment. J Cannabis Ther 1:21-92

52. Ringer S (1886) A handbook of therapeutics. H.K. Lewis, London

53. Hare HA (1887) Clinical and physiological notes on the action of cannabis Indica. There Gaz 11:225-228

54. Suckling C (1891) On the therapeutic value of Indian hemp. Br Med J 2:11-12

55. Mikuriya TH (1991) Chronic migraine headache: five cases successfully treated with marinol and/or illicit cannabis. Schaffer Library of Drug Policy, Berkeley

56. Nicolodi M, Sandoval V, Terrine A. Therapeutic use of cannabinoids - dose finding, effects, and pilot data of effects in chronic migraine and cluster headache. Abstract presentation at 3rd congress of the European Academy of Neurology (EAN), Amsterdam, 2017

57. Robbins MS, Tarshish S, Solomon S, Grosberg BM (2009) Cluster attacks responsive to recreational cannabis and dronabinol. Headache 49:914-916

58. Leroux E, Taifas I, Valade D, Donnet A, Chagnon M, Ducros A (2013) Use of cannabis among 139 cluster headache sufferers. Cephalalgia 33:208-213

59. Donnet A, Lanteri-Minet M, Guegan-Massardier E et al (2007) Chronic cluster headache: a French clinical descriptive study. J Neurol Neurosurg Psychiatry 78:1354-1358

60. Noyes R Jr, Baram DA (1974) Cannabis analgesia. Compr Psychiatry 15:531-535

61. Nunberg H, Kilmer B, Pacula RL, Burgdorf J (2011) An analysis of applicants presenting to a medical marijuana specialty practice in California. J Drug Policy Anal 4(1):1-14

62. Pini LA, Guerzoni S, Cainazzo MM et al (2012) Nabilone for the treatment of medication overuse headache: results of a preliminary double-blind, activecontrolled, randomized trial. J Headache Pain 13:677-684

63. Evans RW, Ramadan NM (2004) Are cannabis-based chemicals helpful in headache? Headache 44:726-727

64. Consroe P, Musty R, Rein J, Tillery W, Pertwee R (1997) The perceived effects of smoked cannabis on patients with multiple sclerosis. Eur Neurol 38:44-48

65. Lochte BC, Beletsky A, Samuel NK, Grant I (2017) The use of cannabis for headache disorders. Cannabis Cannabinoid Res 2:61-71

66. A Multicenter, Randomized, Double-blind, Parallel-group, Placebo-controlled, Efficacy, Safety and Tolerability Study of Dronabinol MDI in the Acute Treatment of Migraine Headache. ClinicalTrials.gov Identifier: NCT00123201. Global Clinical Director Solvay Pharmaceuticals. https://clinicaltrials.gov/ct2/ show/study/NCT00123201. Accessed 15 Dec 2017

67. Lipton RB, Dodick D, Sadovsky R et al (2003) A self-administered screener for migraine in primary care: the ID migraine validation study. Neurology 61: 375-382

68. Akerman S, Holland PR, Lasalandra MP, Goadsby PJ (2013) Endocannabinoids in the brainstem modulate dural trigeminovascular 
nociceptive traffic via CB1 and "triptan" receptors: implications in migraine. J Neurosci 33:14869-14877

69. Akerman S, Holland PR, Goadsby PJ (2007) Cannabinoid (CB1) receptor activation inhibits trigeminovascular neurons. J Pharmacol Exp Ther 320:64-71

70. Akerman S, Kaube H, Goadsby PJ (2004) Anandamide is able to inhibit trigeminal neurons using an in vivo model of trigeminovascular-mediated nociception. J Pharmacol Exp Ther 309:56-63

71. Serrano A, Parsons LH (2011) Endocannabinoid influence in drug reinforcement, dependence and addiction-related behaviors. Pharmacol Ther 132:215-241

72. Rodriguez de Fonseca F, Del Arco I, Bermudez-Silva FJ, Bilbao A, Cippitelli A, Navarro M (2005) The endocannabinoid system: physiology and pharmacology. Alcohol Alcohol 40:2-14

73. Maccarrone M, Gasperi V, Catani MV et al (2010) The endocannabinoid system and its relevance for nutrition. Annu Rev Nutr 30:423-440

74. Howlett AC (2004) Efficacy in CB1 receptor-mediated signal transduction. Br J Pharmacol 142:1209-1218

75. Mallat A, Teixeira-Clerc F, Deveaux V, Manin S, Lotersztajn S (2011) The endocannabinoid system as a key mediator during liver diseases: new insights and therapeutic openings. Br J Pharmacol 163:1432-1440

76. Galve-Roperh I, Rueda D, Gomez del Pulgar T, Velasco G, Guzman M (2002) Mechanism of extracellular signal-regulated kinase activation by the $\mathrm{CB}(1)$ cannabinoid receptor. Mol Pharmacol 62:1385-1392

77. Ryberg E, Larsson N, Sjogren S et al (2007) The orphan receptor GPR55 is a novel cannabinoid receptor. Br J Pharmacol 152:1092-1101

78. De Petrocellis L, Di Marzo V (2009) An introduction to the endocannabinoid system: from the early to the latest concepts. Best Pract Res Clin Endocrinol Metab 23:1-15

79. Devane WA, Hanus L, Breuer A et al (1992) Isolation and structure of a brain constituent that binds to the cannabinoid receptor. Science 258:1946-1949

80. Battista N, Di Tommaso M, Bari M, Maccarrone M (2012) The endocannabinoid system: an overview. Front Behav Neurosci 6:9

81. Di Marzo V, Piscitelli F, Mechoulam R (2011) Cannabinoids and endocannabinoids in metabolic disorders with focus on diabetes. Handb Exp Pharmacol (203):75-104. https://doi.org/10.1007/978-3-642-17214-4_4

82. Di Marzo V, Petrocellis LD (2006) Plant, synthetic, and endogenous cannabinoids in medicine. Annu Rev Med 57:553-574

83. Pertwee RG (2008) The diverse CB1 and CB2 receptor pharmacology of three plant cannabinoids: delta9-tetrahydrocannabinol, cannabidiol and delta9-tetrahydrocannabivarin. Br J Pharmacol 153:199-215

84. Guindon J, Hohmann AG (2009) The endocannabinoid system and pain. CNS Neurol Disord Drug Targets 8:403-421

85. Guindon J, Beaulieu P (2009) The role of the endogenous cannabinoid system in peripheral analgesia. Curr Mol Pharmacol 2:134-139

86. Kraft B (2012) Is there any clinically relevant cannabinoid-induced analgesia? Pharmacology 89:237-246

87. Ramikie TS, Nyilas R, Bluett RJ et al (2014) Multiple mechanistically distinct modes of endocannabinoid mobilization at central amygdala glutamatergic synapses. Neuron 81:1111-1125

88. Grant I, Atkinson JH, Gouaux B, Wilsey B (2012) Medical marijuana: clearing away the smoke. Open Neurol I 6:18-25

89. Pertwee RG, Howlett AC, Abood ME et al (2010) International Union of Basic and Clinical Pharmacology. LXXIX. Cannabinoid receptors and their ligands: beyond $\mathrm{CB}(1)$ and $\mathrm{CB}(2)$. Pharmacol Rev 62:588-631

90. Katona I, Freund TF (2008) Endocannabinoid signaling as a synaptic circuit breaker in neurological disease. Nat Med 14:923-930

91. Raichlen DA, Foster AD, Gerdeman GL, Seillier A, Giuffrida A (2012) Wired to run: exercise-induced endocannabinoid signaling in humans and cursorial mammals with implications for the 'runner's high'. J Exp Biol 215:1331-1336

92. Iversen $L$ (2003) Cannabis and the brain. Brain 126:1252-1270

93. Napchan U, Buse DC, Loder EW (2011) The use of marijuana or synthetic cannabinoids for the treatment of headache. Headache 51:502-505

94. Mackie K (2008) Signaling via CNS cannabinoid receptors. Mol Cell Endocrinol 286:S60-S65

95. Klein TW, Cabral GA (2006) Cannabinoid-induced immune suppression and modulation of antigen-presenting cells. J Neurolmmune Pharmacol 1:50-64

96. Zhang HY, Gao M, Liu QR et al (2014) Cannabinoid CB2 receptors modulate midbrain dopamine neuronal activity and dopamine-related behavior in mice. Proc Natl Acad Sci U S A 111:E5007-E5015

97. Zhang HY, Gao M, Shen $\mathrm{H}$ et al (2017) Expression of functional cannabinoid CB2 receptor in VTA dopamine neurons in rats. Addict Biol 22:752-765
98. Gould J (2015) The cannabis crop. Nature 525:S2-S3

99. Andre CM, Hausman JF, Guerriero G (2016) Cannabis sativa: the plant of the thousand and one molecules. Front Plant Sci 7:19

100. Russo EB (2011) Taming THC: potential cannabis synergy and phytocannabinoid-terpenoid entourage effects. Br J Pharmacol 163:1344-1364

101. Pertwee RG (2010) Receptors and channels targeted by synthetic cannabinoid receptor agonists and antagonists. Curr Med Chem 17:1360-1381

102. Hajos N, Ledent C, Freund TF (2001) Novel cannabinoid-sensitive receptor mediates inhibition of glutamatergic synaptic transmission in the hippocampus. Neuroscience 106:1-4

103. Govaerts SJ, Hermans E, Lambert DM (2004) Comparison of cannabinoid ligands affinities and efficacies in murine tissues and in transfected cells expressing human recombinant cannabinoid receptors. Eur J Pharm Sci 23: 233-243

104. Marcu JP (2016) An overview of major and minor phytocannabinoids. In: Preedy V (ed) Neuropathology of drug addictions and substance misuse, Volume 1: foundations of understanding, tobacco, alcohol, cannabinoids and opioids. Academic Press, London, pp 672-678

105. O'Sullivan SE, Kendall DA, Randall MD (2009) Time-dependent vascular effects of endocannabinoids mediated by peroxisome proliferator-activated receptor gamma (PPARgamma). PPAR Res 2009:425289

106. O'Sullivan SE, Kendall DA (2010) Cannabinoid activation of peroxisome proliferator-activated receptors: potential for modulation of inflammatory disease. Immunobiology 215:611-616

107. De Petrocellis L, Orlando P, Moriello AS et al (2012) Cannabinoid actions at TRPV channels: effects on TRPV 3 and TRPV4 and their potential relevance to gastrointestinal inflammation. Acta Physiol (Oxf) 204:255-266

108. De Petrocellis L, Vellani V, Schiano-Moriello A et al (2008) Plant-derived cannabinoids modulate the activity of transient receptor potential channels of ankyrin type-1 and melastatin type-8. J Pharmacol Exp Ther 325:1007-1015

109. De Petrocellis L, Di Marzo V (2010) Non-CB1, non-CB2 receptors for endocannabinoids, plant cannabinoids, and synthetic cannabimimetics: focus on G-protein-coupled receptors and transient receptor potential channels. J Neurolmmune Pharmacol 5:103-121

110. De Petrocellis L, Ligresti A, Moriello AS et al (2011) Effects of cannabinoids and cannabinoid-enriched Cannabis extracts on TRP channels and endocannabinoid metabolic enzymes. Br J Pharmacol 163:1479-1494

111. Barann M, Molderings G, Bruss M, Bonisch H, Urban BW, Gothert M (2002) Direct inhibition by cannabinoids of human 5-HT3A receptors: probable involvement of an allosteric modulatory site. Br J Pharmacol 137:589-596

112. Hejazi N, Zhou C, Oz M, Sun H, Ye JH, Zhang L (2006) Delta9tetrahydrocannabinol and endogenous cannabinoid anandamide directly potentiate the function of glycine receptors. Mol Pharmacol 69:991-997

113. McHugh D, Page J, Dunn E, Bradshaw HB (2012) Delta(9) -tetrahydrocannabinol and $\mathrm{N}$-arachidonyl glycine are full agonists at GPR18 receptors and induce migration in human endometrial HEC-1B cells. Br J Pharmacol 165:2414-2424

114. Hampson AJ, Grimaldi M, Axelrod J, Wink D (1998) Cannabidiol and (-)Delta9-tetrahydrocannabinol are neuroprotective antioxidants. Proc Natl Acad Sci U S A 95:8268-8273

115. Hampson AJ, Bornheim LM, Scanziani M et al (1998) Dual effects of anandamide on NMDA receptor-mediated responses and neurotransmission. J Neurochem 70:671-676

116. Hampson AJ, Grimaldi M, Lolic M, Wink D, Rosenthal R, Axelrod J (2000) Neuroprotective antioxidants from marijuana. Ann N Y Acad Sci 899:274-282

117. Li J, Daughters RS, Bullis C et al (1999) The cannabinoid receptor agonist WIN 55,212-2 mesylate blocks the development of hyperalgesia produced by capsaicin in rats. Pain 81:25-33

118. Russo EB, Jiang HE, Li X et al (2008) Phytochemical and genetic analyses of ancient cannabis from Central Asia. J Exp Bot 59:4171-4182

119. Russo EB (2008) Cannabinoids in the management of difficult to treat pain. Ther Clin Risk Manag 4:245-259

120. Fine PG, Rosenfeld MJ (2013) The endocannabinoid system, cannabinoids, and pain. Rambam Maimonides Med J 4:e0022

121. Welch SP (1993) Blockade of cannabinoid-induced antinociception by norbinaltorphimine, but not N,N-diallyl-tyrosine-Aib-phenylalanine-leucine, ICl 174,864 or naloxone in mice. J Pharmacol Exp Ther 265:633-640

122. Smith FL, Cichewicz D, Martin ZL, Welch SP (1998) The enhancement of morphine antinociception in mice by delta9-tetrahydrocannabinol. Pharmacol Biochem Behav 60:559-566 
123. Smith PA, Selley DE, Sim-Selley LJ, Welch SP (2007) Low dose combination of morphine and delta9-tetrahydrocannabinol circumvents antinociceptive tolerance and apparent desensitization of receptors. Eur J Pharmacol 571:129-137

124. Cichewicz DL, McCarthy EA (2003) Antinociceptive synergy between delta(9)-tetrahydrocannabinol and opioids after oral administration. J Pharmacol Exp Ther 304:1010-1015

125. Cichewicz DL (2004) Synergistic interactions between cannabinoid and opioid analgesics. Life Sci 74:1317-1324

126. Manzanares J, Corchero J, Romero J, Fernandez-Ruiz JJ, Ramos JA, Fuentes JA (1998) Chronic administration of cannabinoids regulates proenkephalin mRNA levels in selected regions of the rat brain. Brain Res Mol Brain Res 55: 126-132

127. Manzanares J, Julian M, Carrascosa A (2006) Role of the cannabinoid system in pain control and therapeutic implications for the management of acute and chronic pain episodes. Curr Neuropharmacol 4:239-257

128. Evans FJ (1991) Cannabinoids: the separation of central from peripheral effects on a structural basis. Planta Med 57:S60-S67

129. Brown AJ (2007) Novel cannabinoid receptors. Br J Pharmacol 152:567-575

130. Izzo AA, Borrelli F, Capasso R, Di Marzo V, Mechoulam R (2009) Nonpsychotropic plant cannabinoids: new therapeutic opportunities from an ancient herb. Trends Pharmacol Sci 30:515-527

131. Rahn E, Hohmann AG (2009) Cannabinoids as pharmacotherapies for neuropathic pain: from the bench to the bedside. Neurotherapeutics 6:713-737

132. Pacher P, Batkai S, Kunos G (2006) The endocannabinoid system as an emerging target of pharmacotherapy. Pharmacol Rev 58:389-462

133. Noyes R Jr, Brunk SF, Avery DA, Canter AC (1975) The analgesic properties of delta-9-tetrahydrocannabinol and codeine. Clin Pharmacol Ther 18:84-89

134. Noyes R Jr, Brunk SF, Baram DA, Canter A (1975) Analgesic effect of delta-9tetrahydrocannabinol. J Clin Pharmacol 15:139-143

135. Schley M, Legler A, Skopp G, Schmelz M, Konrad C, Rukwied R (2006) Delta-9THC based monotherapy in fibromyalgia patients on experimentally induced pain, axon reflex flare, and pain relief. Curr Med Res Opin 22:1269-1276

136. Maurer M, Henn V, Dittrich A, Hofmann A (1990) Delta-9tetrahydrocannabinol shows antispastic and analgesic effects in a single case double-blind trial. Eur Arch Psychiatry Clin Neurosci 240:1-4

137. Srivastava MD, Srivastava BI, Brouhard B (1998) Delta9 tetrahydrocannabinol and cannabidiol alter cytokine production by human immune cells. Immunopharmacology 40:179-185

138. Kozela E, Pietr M, Juknat A, Rimmerman N, Levy R, Vogel Z (2010) Cannabinoids Delta(9)-tetrahydrocannabinol and cannabidiol differentially inhibit the lipopolysaccharide-activated NF-kappaB and interferon-beta/STAT proinflammatory pathways in BV-2 microglial cells. J Biol Chem 285:1616-1626

139. Barrie N, Manolios N (2017) The endocannabinoid system in pain and inflammation: its relevance to rheumatic disease. Eur J Rheumatol 4 : 210-218

140. Ruhaak LR, Felth J, Karlsson PC, Rafter JJ, Verpoorte R, Bohlin L (2011) Evaluation of the cyclooxygenase inhibiting effects of six major cannabinoids isolated from cannabis sativa. Biol Pharm Bull 34:774-778

141. Martin BR, Compton DR, Thomas BF et al (1991) Behavioral, biochemical, and molecular modeling evaluations of cannabinoid analogs. Pharmacol Biochem Behav 40:471-478

142. Martin BR, Lichtman AH (1998) Cannabinoid transmission and pain perception. Neurobiol Dis 5:447-461

143. DeLong GT, Wolf CE, Poklis A, Lichtman AH (2010) Pharmacological evaluation of the natural constituent of cannabis sativa, cannabichromene and its modulation by Delta(9)-tetrahydrocannabinol. Drug Alcohol Depend 112:126-133

144. Zygmunt PM, Andersson DA, Hogestatt ED (2002) Delta 9tetrahydrocannabinol and cannabinol activate capsaicin-sensitive sensory nerves via a CB1 and CB2 cannabinoid receptor-independent mechanism. J Neurosci 22:4720-4727

145. Burston JJ, Sagar DR, Shao P et al (2013) Cannabinoid CB2 receptors regulate central sensitization and pain responses associated with osteoarthritis of the knee joint. PLoS One 8:e80440

146. Gui H, Liu X, Wang ZW, He DY, Su DF, Dai SM (2014) Expression of cannabinoid receptor 2 and its inhibitory effects on synovial fibroblasts in rheumatoid arthritis. Rheumatology (Oxford) 53:802-809

147. Clayton N, Marshall FH, Bountra C, O'Shaughnessy CT (2002) CB1 and CB2 cannabinoid receptors are implicated in inflammatory pain. Pain 96:253-260
148. Nagarkatti P, Pandey R, Rieder SA, Hegde VL, Nagarkatti M (2009) Cannabinoids as novel anti-inflammatory drugs. Future Med Chem 1:1333-1349

149. Jensen B, Chen J, Furnish T, Wallace M (2015) Medical marijuana and chronic pain: a review of basic science and clinical evidence. Curr Pain Headache Rep 19:50

150. Weber J, Schley M, Casutt M et al (2009) Tetrahydrocannabinol (Delta 9THC) treatment in chronic central neuropathic pain and fibromyalgia patients: results of a multicenter survey. Anesthesiol Res Pract 2009. https://doi.org/10.1155/2009/827290 Epub 2009 Oct 25

151. Weber M, Goldman B, Truniger S (2010) Tetrahydrocannabinol (THC) for cramps in amyotrophic lateral sclerosis: a randomised, double-blind crossover trial. J Neurol Neurosurg Psychiatry 81:1135-1140

152. Smith PB, Martin BR (1992) Spinal mechanisms of delta 9tetrahydrocannabinol-induced analgesia. Brain Res 578:8-12

153. Smith FL, Fujimori K, Lowe J, Welch SP (1998) Characterization of delta9tetrahydrocannabinol and anandamide antinociception in nonarthritic and arthritic rats. Pharmacol Biochem Behav 60:183-191

154. Walker JM, Huang SM (2002) Cannabinoid analgesia. Pharmacol Ther 95:127-135

155. Walker JM, Strangman NM, Huang SM (2001) Cannabinoids and pain. Pain Res Manag 6:74-79

156. Walker JM, Hohmann AG, Martin WJ, Strangman NM, Huang SM, Tsou K (1999) The neurobiology of cannabinoid analgesia. Life Sci 65:665-673

157. Ware MA, Wang T, Shapiro S et al (2010) Smoked cannabis for chronic neuropathic pain: a randomized controlled trial. CMAJ 182:E694-E701

158. Wilsey B, Marcotte T, Deutsch R, Gouaux B, Sakai S, Donaghe H (2013) Lowdose vaporized cannabis significantly improves neuropathic pain. J Pain 14: 136-148

159. Wilsey B, Marcotte T, Tsodikov A et al (2008) A randomized, placebocontrolled, crossover trial of cannabis cigarettes in neuropathic pain. J Pain 9:506-521

160. Ellis RJ, Toperoff W, Vaida F et al (2009) Smoked medicinal cannabis for neuropathic pain in HIV: a randomized, crossover clinical trial. Neuropsychopharmacology 34:672-680

161. Abrams DI, Jay CA, Shade SB et al (2007) Cannabis in painful HIV-associated sensory neuropathy: a randomized placebo-controlled trial. Neurology 68: 515-521

162. Corey-Bloom J, Wolfson T, Gamst A et al (2012) Smoked cannabis for spasticity in multiple sclerosis: a randomized, placebo-controlled trial. CMAJ 184:1143-1150

163. Wallace MS, Marcotte TD, Umlauf A, Gouaux B, Atkinson JH (2015) Efficacy of inhaled cannabis on painful diabetic neuropathy. J Pain 16:616-627

164. Wallace M, Schulteis G, Atkinson JH et al (2007) Dose-dependent effects of smoked cannabis on capsaicin-induced pain and hyperalgesia in healthy volunteers. Anesthesiology 107:785-796

165. Greenwald MK, Stitzer ML (2000) Antinociceptive, subjective and behavioral effects of smoked marijuana in humans. Drug Alcohol Depend 59:261-275

166. Abrams DI, Couey P, Shade SB, Kelly ME, Benowitz NL (2011) Cannabinoidopioid interaction in chronic pain. Clin Pharmacol Ther 90:844-851

167. Eisenberg E, Ogintz M, Almog S (2014) The pharmacokinetics, efficacy, safety, and ease of use of a novel portable metered-dose cannabis inhaler in patients with chronic neuropathic pain: a phase 1a study. J Pain Palliat Care Pharmacother 28:216-225

168. Ware MA, Wang T, Shapiro S, Collet JP (2015) COMPASS study team. Cannabis for the Management of Pain: Assessment of Safety Study (COMPASS). J Pain 16:1233-1242

169. Fiz J, Duran M, Capella D, Carbonell J, Farre M (2011) Cannabis use in patients with fibromyalgia: effect on symptoms relief and health-related quality of life. PLoS One 6:e18440

170. Ben-Shabat S, Fride E, Sheskin T et al (1998) An entourage effect: inactive endogenous fatty acid glycerol esters enhance 2-arachidonoyl-glycerol cannabinoid activity. Eur J Pharmacol 353:23-31

171. Nurmikko TJ, Serpell MG, Hoggart B, Toomey PJ, Morlion BJ, Haines D (2007) Sativex successfully treats neuropathic pain characterised by allodynia: a randomised, double-blind, placebo-controlled clinical trial. Pain 133:210-220

172. Rog DJ, Nurmikko TJ, Young CA (2007) Oromucosal delta9tetrahydrocannabinol/cannabidiol for neuropathic pain associated with multiple sclerosis: an uncontrolled, open-label, 2-year extension trial. Clin Ther 29:2068-2079

173. Rog DJ, Nurmikko TJ, Friede T, Young CA (2005) Randomized, controlled trial of cannabis-based medicine in central pain in multiple sclerosis. Neurology 65:812-819 
174. Blake DR, Robson P, Ho M, Jubb RW, McCabe CS (2006) Preliminary assessment of the efficacy, tolerability and safety of a cannabis-based medicine (Sativex) in the treatment of pain caused by rheumatoid arthritis. Rheumatology (Oxford) 45:50-52

175. Serpell MG, Notcutt W, Collin C (2013) Sativex long-term use: an openlabel trial in patients with spasticity due to multiple sclerosis. J Neurol 260:285-295

176. Wade DT, Makela PM, House H, Bateman C, Robson P (2006) Long-term use of a cannabis-based medicine in the treatment of spasticity and other symptoms in multiple sclerosis. Mult Scler 12:639-645

177. Portenoy RK, Ganae-Motan ED, Allende S et al (2012) Nabiximols for opioidtreated cancer patients with poorly-controlled chronic pain: a randomized, placebo-controlled, graded-dose trial. J Pain 13:438-449

178. Wade DT, Robson P, House H, Makela P, Aram J (2003) A preliminary controlled study to determine whether whole-plant cannabis extracts can improve intractable neurogenic symptoms. Clin Rehabil 17:21-29

179. Notcutt W, Price M, Miller R et al (2004) Initial experiences with medicinal extracts of cannabis for chronic pain: results from 34 ' $\mathrm{N}$ of 1 ' studies. Anaesthesia 59:440-452

180. Notcutt W, Langford R, Davies P, Ratcliffe S, Potts R (2012) A placebocontrolled, parallel-group, randomized withdrawal study of subjects with symptoms of spasticity due to multiple sclerosis who are receiving longterm Sativex(R) (nabiximols). Mult Scler 18:219-228

181. Berman JS, Symonds C, Birch R (2004) Efficacy of two cannabis based medicinal extracts for relief of central neuropathic pain from brachial plexus avulsion: results of a randomised controlled trial. Pain 112:299-306

182. Langford RM, Mares J, Novotna A et al (2013) A double-blind, randomized, placebo-controlled, parallel-group study of THC/CBD oromucosal spray in combination with the existing treatment regimen, in the relief of central neuropathic pain in patients with multiple sclerosis. J Neurol 260:984-997

183. Johnson JR, Burnell-Nugent M, Lossignol D, Ganae-Motan ED, Potts R, Fallon MT (2010) Multicenter, double-blind, randomized, placebo-controlled, parallel-group study of the efficacy, safety, and tolerability of THC:CBD extract and THC extract in patients with intractable cancer-related pain. J Pain Symptom Manag 39:167-179

184. Johnson JR, Lossignol D, Burnell-Nugent M, Fallon MT (2013) An open-label extension study to investigate the long-term safety and tolerability of $\mathrm{THC}$ / CBD oromucosal spray and oromucosal THC spray in patients with terminal cancer-related pain refractory to strong opioid analgesics. J Pain Symptom Manag 46:207-218

185. Zajicek JP, Sanders HP, Wright DE et al (2005) Cannabinoids in multiple sclerosis (CAMS) study: safety and efficacy data for 12 months follow up. J Neurol Neurosurg Psychiatry 76:1664-1669

186. Zajicek JP, Apostu VI (2011) Role of cannabinoids in multiple sclerosis. CNS Drugs 25:187-201

187. Zajicek JP, Hobart JC, Slade A, Barnes D, Mattison PG, MUSEC Research Group (2012) Multiple sclerosis and extract of cannabis: results of the MUSEC trial. J Neurol Neurosurg Psychiatry 83:1125-1132

188. Zajicek J, Fox P, Sanders H et al (2003) Cannabinoids for treatment of spasticity and other symptoms related to multiple sclerosis (CAMS study): multicentre randomised placebo-controlled trial. Lancet 362:1517-1526

189. Vaney C, Heinzel-Gutenbrunner M, Jobin P et al (2004) Efficacy, safety and tolerability of an orally administered cannabis extract in the treatment of spasticity in patients with multiple sclerosis: a randomized, double-blind, placebo-controlled, crossover study. Mult Scler 10:417-424

190. Collin C, Davies P, Mutiboko IK, Ratcliffe S, Sativex Spasticity in MS Study Group (2007) Randomized controlled trial of cannabis-based medicine in spasticity caused by multiple sclerosis. Eur J Neurol 14:290-296

191. Collin C, Ehler E, Waberzinek G et al (2010) A double-blind, randomized, placebo-controlled, parallel-group study of Sativex, in subjects with symptoms of spasticity due to multiple sclerosis. Neurol Res 32:451-459

192. Wade DT, Makela P, Robson P, House H, Bateman C (2004) Do cannabisbased medicinal extracts have general or specific effects on symptoms in multiple sclerosis? A double-blind, randomized, placebo-controlled study on 160 patients. Mult Scler 10:434-441

193. Serpell M, Ratcliffe S, Hovorka J et al (2014) A double-blind, randomized, placebo-controlled, parallel group study of THC/CBD spray in peripheral neuropathic pain treatment. Eur J Pain 18:999-1012

194. Syed YY, McKeage K, Scott LJ (2014) Delta-9-tetrahydrocannabinol/ cannabidiol (Sativex $(\mathrm{R}))$ : a review of its use in patients with moderate to severe spasticity due to multiple sclerosis. Drugs 74:563-578
195. Lakhan SE, Rowland M (2009) Whole plant cannabis extracts in the treatment of spasticity in multiple sclerosis: a systematic review. BMC Neurol 9:59

196. Barnes MP (2006) Sativex: clinical efficacy and tolerability in the treatment of symptoms of multiple sclerosis and neuropathic pain. Expert Opin Pharmacother 7:607-615

197. GW Pharmaceuticals. Sativex product monograph., 2010

198. Holdcroft A, Maze M, Dore C, Tebbs S, Thompson S (2006) A multicenter dose-escalation study of the analgesic and adverse effects of an oral cannabis extract (Cannador) for postoperative pain management. Anesthesiology 104:1040-1046

199. Sallan SE, Zinberg NE, Frei E 3rd (1975) Antiemetic effect of delta-9tetrahydrocannabinol in patients receiving cancer chemotherapy. N Engl J Med 293:795-797

200. Sallan SE, Cronin C, Zelen M, Zinberg NE (1980) Antiemetics in patients receiving chemotherapy for cancer: a randomized comparison of delta-9tetrahydrocannabinol and prochlorperazine. N Engl J Med 302:135-138

201. Vinciguerra $V$, Moore $T$, Brennan $E$ (1988) Inhalation marijuana as an antiemetic for cancer chemotherapy. N Y State J Med 88:525-527

202. Carey MP, Burish TG, Brenner DE (1983) Delta-9-tetrahydrocannabinol in cancer chemotherapy: research problems and issues. Ann Intern Med 99: $106-114$

203. Lucas VS Jr, Laszlo J (1980) delta 9-tetrahydrocannabinol for refractory vomiting induced by cancer chemotherapy. JAMA 243:1241-1243

204. Frytak S, Moertel CG, O'Fallon JR et al (1979) Delta-9-tetrahydrocannabinol as an antiemetic for patients receiving cancer chemotherapy. A comparison with prochlorperazine and a placebo. Ann Intern Med 91:825-830

205. Ungerleider JT, Andrysiak T, Fairbanks L, Goodnight J, Sarna G, Jamison K (1982) Cannabis and cancer chemotherapy: a comparison of oral delta-9THC and prochlorperazine. Cancer 50:636-645

206. Orr LE, McKernan JF, Bloome B (1980) Antiemetic effect of tetrahydrocannabinol. Compared with placebo and prochlorperazine in chemotherapy-associated nausea and emesis. Arch Intern Med 140: $1431-1433$

207. Orr LE, McKernan JF (1981) Antiemetic effect of delta 9tetrahydrocannabinol in chemotherapy-associated nausea and emesis as compared to placebo and compazine. J Clin Pharmacol 21:76S-80S

208. Levitt M, Wilson A, Bowman D et al (1981) Physiologic observations in a controlled clinical trial of the antiemetic effectiveness of 5, 10, and $15 \mathrm{mg}$ of delta 9-tetrahydrocannabinol in cancer chemotherapy. Ophthalmologic implications. J Clin Pharmacol 21:103S-109S

209. McCabe M, Smith FP, Macdonald JS, Woolley PV, Goldberg D, Schein PS (1988) Efficacy of tetrahydrocannabinol in patients refractory to standard antiemetic therapy. Investig New Drugs 6:243-246

210. Niiranen A, Mattson K (1985) A cross-over comparison of nabilone and prochlorperazine for emesis induced by cancer chemotherapy. Am J Clin Oncol 8:336-340

211. Herman TS, Einhorn LH, Jones SE et al (1979) Superiority of nabilone over prochlorperazine as an antiemetic in patients receiving cancer chemotherapy. N Engl J Med 300:1295-1297

212. Vincent BJ, McQuiston DJ, Einhorn LH, Nagy CM, Brames MJ (1983) Review of cannabinoids and their antiemetic effectiveness. Drugs 25(Suppl 1):52-62

213. Einhorn $L$ (1982) Nabilone: an effective antiemetic agent in patients receiving cancer chemotherapy. Cancer Treat Rev 9(Suppl B):55-61

214. Einhorn LH, Nagy C, Furnas B, Williams SD (1981) Nabilone: an effective antiemetic in patients receiving cancer chemotherapy. J Clin Pharmacol 21: 645-69S

215. Ahmedzai S, Carlyle DL, Calder IT, Moran F (1983) Anti-emetic efficacy and toxicity of nabilone, a synthetic cannabinoid, in lung cancer chemotherapy. $\mathrm{Br} J$ Cancer 48:657-663

216. Garb S, Beers AL, Bograd M et al (1980) Two-pronged study of tetrahydrocannabinol (THC) prevention of vomiting for cancer chemotherapy. IRCS Med Sci 8:203-204

217. Lane M, Smith FE, Sullivan RA, Plasse TF (1990) Dronabinol and prochlorperazine alone and in combination as antiemetic agents for cancer chemotherapy. Am J Clin Oncol 13:480-484

218. Lane $M$, Vogel CL, Ferguson J et al (1991) Dronabinol and prochlorperazine in combination for treatment of cancer chemotherapy-induced nausea and vomiting. J Pain Symptom Manag 6:352-359

219. Plasse TF, Gorter RW, Krasnow SH, Lane M, Shepard KV, Wadleigh RG (1991) Recent clinical experience with dronabinol. Pharmacol Biochem Behav 40: 695-700 
220. Cunningham D, Forrest GJ, Soukop M, Gilchrist NL, Calder IT, McArdle CS (1985) Nabilone and prochlorperazine: a useful combination for emesis induced by cytotoxic drugs. Br Med J (Clin Res Ed) 291:864-865

221. Gonzalez-Rosales F, Walsh D (1997) Intractable nausea and vomiting due to gastrointestinal mucosal metastases relieved by tetrahydrocannabinol (dronabinol). J Pain Symptom Manag 14:311-314

222. Chang AE, Shiling DJ, Stillman RC et al (1979) Delata-9tetrahydrocannabinol as an antiemetic in cancer patients receiving high-dose methotrexate. A prospective, randomized evaluation. Ann Intern Med 91:819-824

223. Staquet M, Bron D, Rozencweig M, Kenis Y (1981) Clinical studies with a THC analog (BRL-4664) in the prevention of cisplatin-induced vomiting. J Clin Pharmacol 21:60S-63S

224. Sharkey KA, Darmani NA, Parker LA (2014) Regulation of nausea and vomiting by cannabinoids and the endocannabinoid system. Eur J Pharmacol 722:134-146

225. Parker LA, Rock EM, Limebeer CL (2011) Regulation of nausea and vomiting by cannabinoids. Br J Pharmacol 163:1411-1422

226. Tramer MR, Carroll D, Campbell FA, Reynolds DJ, Moore RA, McQuay HJ (2001) Cannabinoids for control of chemotherapy induced nausea and vomiting: quantitative systematic review. BMJ 323:16-21

227. Sutton IR, Daeninck P (2006) Cannabinoids in the management of intractable chemotherapy-induced nausea and vomiting and cancer-related pain. J Support Oncol 4:531-535

228. Pisanti S, Malfitano AM, Grimaldi C et al (2009) Use of cannabinoid receptor agonists in cancer therapy as palliative and curative agents. Best Pract Res Clin Endocrinol Metab 23:117-131

229. Tortorice PV, O'Connell MB (1990) Management of chemotherapy-induced nausea and vomiting. Pharmacotherapy 10:129-145

230. Cunningham D, Bradley CJ, Forrest GJ et al (1988) A randomized trial of ora nabilone and prochlorperazine compared to intravenous metoclopramide and dexamethasone in the treatment of nausea and vomiting induced by chemotherapy regimens containing cisplatin or cisplatin analogues. Eur J Cancer Clin Oncol 24:685-689

231. Soderpalm AH, Schuster A, de Wit H (2001) Antiemetic efficacy of smoked marijuana: subjective and behavioral effects on nausea induced by syrup of ipecac. Pharmacol Biochem Behav 69:343-350

232. Machado Rocha FC, Stefano SC, De Cassia Haiek R, Rosa Oliveira LM, Da Silveira DX (2008) Therapeutic use of cannabis sativa on chemotherapyinduced nausea and vomiting among cancer patients: systematic review and meta-analysis. Eur J Cancer Care (Engl) 17:431-443

233. Musty R, Rossi R (2001) Effects of smoked cannabis and oral delta-9tetrahydrocannabinol on nausea and emesis after cancer chemotherapy: a review of state clinical trials. J Cannabis Ther 1:29-42

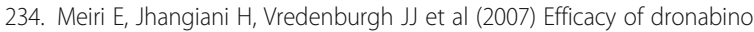
alone and in combination with ondansetron versus ondansetron alone for delayed chemotherapy-induced nausea and vomiting. Curr Med Res Opin 23:533-543

235. Ekert $H$, Waters KD, Jurk $I H$, Mobilia J, Loughnan P (1979) Amelioration of cancer chemotherapy-induced nausea and vomiting by delta-9tetrahydrocannabinol. Med J Aust 2:657-659

236. Pertwee RG (2012) Targeting the endocannabinoid system with cannabinoid receptor agonists: pharmacological strategies and therapeutic possibilities. Philos Trans R Soc Lond Ser B Biol Sci 367: 3353-3363

237. Rock EM, Connolly C, Limebeer CL, Parker LA (2016) Effect of combined oral doses of Delta(9)-tetrahydrocannabinol (THC) and cannabidiolic acid (CBDA) on acute and anticipatory nausea in rat models. Psychopharmacology 233 : 3353-3360

238. Green ST, Nathwani D, Goldberg DJ, Kennedy DH (1989) Nabilone as effective therapy for intractable nausea and vomiting in AIDS. Br J Clin Pharmacol 28:494-495

239. Chan HS, Correia JA, MacLeod SM (1987) Nabilone versus prochlorperazine for control of cancer chemotherapy-induced emesis in children: a doubleblind, crossover trial. Pediatrics 79:946-952

240. Dalzell AM, Bartlett H, Lilleyman JS (1986) Nabilone: an alternative antiemetic for cancer chemotherapy. Arch Dis Child 61:502-505

241. Abrahamov A, Abrahamov A, Mechoulam R (1995) An efficient new cannabinoid antiemetic in pediatric oncology. Life Sci 56:2097-2102

242. Abbott Products Inc. Marinol product monograph, 2010

243. Valeant Canada. Cesamet product monograph., 2009
244. Narang S, Gibson D, Wasan AD et al (2008) Efficacy of dronabinol as an adjuvant treatment for chronic pain patients on opioid therapy. J Pain 9: 254-264

245. Svendsen KB, Jensen TS, Bach FW (2005) Effect of the synthetic cannabinoid dronabinol on central pain in patients with multiple sclerosis-secondary publication. Ugeskr Laeger 167:2772-2774

246. Svendsen KB, Jensen TS, Bach FW (2004) Does the cannabinoid dronabinol reduce central pain in multiple sclerosis? Randomised double blind placebo controlled crossover trial. BMJ 329:253

247. Skrabek RQ, Galimova L, Ethans K, Perry D (2008) Nabilone for the treatment of pain in fibromyalgia. J Pain 9:164-173

248. Naef M, Curatolo M, Petersen-Felix S, Arendt-Nielsen L, Zbinden A, Brenneisen R (2003) The analgesic effect of oral delta-9tetrahydrocannabinol (THC), morphine, and a THC-morphine combination in healthy subjects under experimental pain conditions. Pain 105:79-88

249. Pinsger M, Schimetta W, Volc D, Hiermann E, Riederer F, Polz W (2006) Benefits of an add-on treatment with the synthetic cannabinomimetic nabilone on patients with chronic pain-a randomized controlled trial. Wien Klin Wochenschr 118:327-335

250. Wissel J, Haydn T, Muller J et al (2006) Low dose treatment with the synthetic cannabinoid Nabilone significantly reduces spasticity-related pain : a double-blind placebo-controlled cross-over trial. J Neurol 253:1337-1341

251. Toth C, Mawani S, Brady S et al (2012) An enriched-enrolment, randomized withdrawal, flexible-dose, double-blind, placebo-controlled, parallel assignment efficacy study of nabilone as adjuvant in the treatment of diabetic peripheral neuropathic pain. Pain 153:2073-2082

252. Turcotte D, Doupe M, Torabi M et al (2015) Nabilone as an adjunctive to gabapentin for multiple sclerosis-induced neuropathic pain: a randomized controlled trial. Pain Med 16:149-159

253. Notcutt WG, Price M, Chapman G (1997) Clinical experience with nabilone for chronic pain. Pharm Sci 3:551-555

254. Hamann W, di Vadi PP (1999) Analgesic effect of the cannabinoid analogue nabilone is not mediated by opioid receptors. Lancet 353:560

255. Berlach DM, Shir Y, Ware MA (2006) Experience with the synthetic cannabinoid nabilone in chronic noncancer pain. Pain Med 7:25-29

256. Martyn CN, Illis LS, Thom J (1995) Nabilone in the treatment of multiple sclerosis. Lancet 345:579

257. Cannabidiol (CBD) Pre-Review Report. World Health Organization: Expert Committee on Drug Dependence. http://www.who.int/medicines/access/ controlled-substances/5.2 CBD.pdf. Accessed 20 Dec 2017

258. "Prohibited List: January 2018". The World Anti-Doping Code International Standard. World Anti-Doping Agency (WADA). https://www.wada-ama.org/ sites/default/files/prohibited_list_2018_en.pdf. Accessed 23 Apr 2018

259. Zuardi AW (2008) Cannabidiol: from an inactive cannabinoid to a drug with wide spectrum of action. Rev Bras Psiquiatr 30:271-280

260. Mechoulam R, Parker LA, Gallily R (2002) Cannabidiol: an overview of some pharmacological aspects. J Clin Pharmacol 42:11S-19S

261. Pagano E, Capasso R, Piscitelli $F$ et al (2016) An orally active Cannabis extract with high content in cannabidiol attenuates chemically-induced intestinal inflammation and hypermotility in the mouse. Front Pharmacol 7:341

262. Mechoulam R, Peters M, Murillo-Rodriguez E, Hanus LO (2007) Cannabidiolrecent advances. Chem Biodivers 4:1678-1692

263. Malfait AM, Gallily R, Sumariwalla PF et al (2000) The nonpsychoactive cannabis constituent cannabidiol is an oral anti-arthritic therapeutic in murine collagen-induced arthritis. Proc Natl Acad Sci U S A 97:9561-9566

264. Formukong EA, Evans AT, Evans FJ (1988) Analgesic and antiinflammatory activity of constituents of cannabis sativa L. Inflammation 12:361-371

265. Formukong EA, Evans AT, Evans FJ (1989) The medicinal uses of cannabis and its constituents. Phytother Res 3:219-231

266. Costa B, Trovato AE, Comelli F, Giagnoni G, Colleoni M (2007) The nonpsychoactive cannabis constituent cannabidiol is an orally effective therapeutic agent in rat chronic inflammatory and neuropathic pain. Eur $J$ Pharmacol 556:75-83

267. Costa B, Colleoni M, Conti S et al (2004) Oral anti-inflammatory activity of cannabidiol, a non-psychoactive constituent of cannabis, in acute carrageenan-induced inflammation in the rat paw. Naunyn Schmiedeberg's Arch Pharmacol 369:294-299

268. Booz GW (2011) Cannabidiol as an emergent therapeutic strategy for lessening the impact of inflammation on oxidative stress. Free Radic Bio Med 51:1054-1061 
269. McHugh D, Tanner C, Mechoulam R, Pertwee RG, Ross RA (2008) Inhibition of human neutrophil chemotaxis by endogenous cannabinoids and phytocannabinoids: evidence for a site distinct from CB1 and CB2. Mol Pharmacol 73:441-450

270. Zhornitsky S, Potvin S (2012) Cannabidiol in humans-the quest for therapeutic targets. Pharmaceuticals (Basel) 5:529-552

271. Ribeiro A, Almeida VI, Costola-de-Souza C et al (2015) Cannabidiol improves lung function and inflammation in mice submitted to LPS-induced acute lung injury. Immunopharmacol Immunotoxicol 37:35-41

272. Ribeiro A, Ferraz-de-Paula V, Pinheiro ML et al (2012) Cannabidiol, a nonpsychotropic plant-derived cannabinoid, decreases inflammation in a murine model of acute lung injury: role for the adenosine $A(2 A)$ receptor. Eur J Pharmacol 678:78-85

273. Kozela E, Lev N, Kaushansky N et al (2011) Cannabidiol inhibits pathogenic T cells, decreases spinal microglial activation and ameliorates multiple sclerosis-like disease in C57BL/6 mice. Br J Pharmacol 163:1507-1519

274. Mecha M, Feliu A, Inigo PM, Mestre L, Carrillo-Salinas FJ, Guaza C (2013) Cannabidiol provides long-lasting protection against the deleterious effects of inflammation in a viral model of multiple sclerosis: a role for A2A receptors. Neurobiol Dis 59:141-150

275. Mecha M, Torrao AS, Mestre L, Carrillo-Salinas FJ, Mechoulam R, Guaza C (2012) Cannabidiol protects oligodendrocyte progenitor cells from inflammation-induced apoptosis by attenuating endoplasmic reticulum stress. Cell Death Dis 3:e331

276. Thomas A, Baillie GL, Phillips AM, Razdan RK, Ross RA, Pertwee RG (2007) Cannabidiol displays unexpectedly high potency as an antagonist of CB1 and CB2 receptor agonists in vitro. Br J Pharmacol 150:613-623

277. Comelli F, Bettoni I, Colleoni M, Giagnoni G, Costa B (2009) Beneficial effects of a cannabis sativa extract treatment on diabetes-induced neuropathy and oxidative stress. Phytother Res 23:1678-1684

278. Comelli F, Giagnoni G, Bettoni I, Colleoni M, Costa B (2008) Antihyperalgesic effect of a cannabis sativa extract in a rat model of neuropathic pain: mechanisms involved. Phytother Res 22:1017-1024

279. Kohli DR, Li Y, Khasabov SG et al (2010) Pain-related behaviors and neurochemical alterations in mice expressing sickle hemoglobin: modulation by cannabinoids. Blood 116:456-465

280. Howard J, Anie KA, Holdcroft A, Korn S, Davies SC (2005) Cannabis use in sickle cell disease: a questionnaire study. $\mathrm{Br} J$ Haematol 131:123-128

281. Maione S, Piscitelli F, Gatta L et al (2011) Non-psychoactive cannabinoids modulate the descending pathway of antinociception in anaesthetized rats through several mechanisms of action. Br J Pharmacol 162:584-596

282. Williamson EM, Evans FJ (2000) Cannabinoids in clinical practice. Drugs 60: 1303-1314

283. Russo E, Guy GW (2006) A tale of two cannabinoids: the therapeutic rationale for combining tetrahydrocannabinol and cannabidiol. Med Hypotheses 66:234-246

284. Murillo-Rodriguez E, Millan-Aldaco D, Palomero-Rivero M, Mechoulam R, Drucker-Colin R (2006) Cannabidiol, a constituent of cannabis sativa, modulates sleep in rats. FEBS Lett 580:4337-4345

285. Nicholson AN, Turner C, Stone BM, Robson PJ (2004) Effect of Delta9-tetrahydrocannabinol and cannabidiol on nocturnal sleep and earlymorning behavior in young adults. J Clin Psychopharmacol 24:305313

286. Zuardi AW, Hallak JE, Crippa JA (2012) Interaction between cannabidiol (CBD) and (9)-tetrahydrocannabinol (THC): influence of administration interval and dose ratio between the cannabinoids. Psychopharmacology 219:247-249

287. Zuardi AW, Shirakawa I, Finkelfarb E, Karniol IG (1982) Action of cannabidiol on the anxiety and other effects produced by delta 9-THC in normal subjects. Psychopharmacology 76:245-250

288. Zuardi AW, Finkelfarb E, Bueno OF, Musty RE, Karniol IG (1981) Characteristics of the stimulus produced by the mixture of cannabidiol with delta 9-tetrahydrocannabinol. Arch Int Pharmacodyn Ther 249:137-146

289. Bisogno T, Hanus L, De Petrocellis $L$ et al (2001) Molecular targets for cannabidiol and its synthetic analogues: effect on vanilloid VR1 receptors and on the cellular uptake and enzymatic hydrolysis of anandamide. $\mathrm{Br} J$ Pharmacol 134:845-852

290. Ligresti A, Moriello AS, Starowicz K et al (2006) Antitumor activity of plant cannabinoids with emphasis on the effect of cannabidiol on human breast carcinoma. J Pharmacol Exp Ther 318:1375-1387
291. Ahrens J, Demir R, Leuwer M et al (2009) The nonpsychotropic cannabinoid cannabidiol modulates and directly activates alpha-1 and alpha-1-Beta glycine receptor function. Pharmacology 83:217-222

292. Qin N, Neeper MP, Liu Y, Hutchinson TL, Lubin ML, Flores CM (2008) TRPV2 is activated by cannabidiol and mediates CGRP release in cultured rat dorsal root ganglion neurons. J Neurosci 28:6231-6238

293. Ross HR, Napier I, Connor M (2008) Inhibition of recombinant human T-type calcium channels by Delta9-tetrahydrocannabinol and cannabidiol. J Biol Chem 283:16124-16134

294. Jenny M, Santer E, Pirich E, Schennach H, Fuchs D (2009) Delta9tetrahydrocannabinol and cannabidiol modulate mitogen-induced tryptophan degradation and neopterin formation in peripheral blood mononuclear cells in vitro. J Neuroimmunol 207:75-82

295. Evans AT, Formukong E, Evans FJ (1987) Activation of phospholipase A2 by cannabinoids. Lack of correlation with CNS effects. FEBS Lett 211:119-122

296. Russo EB, Burnett A, Hall B, Parker KK (2005) Agonistic properties of cannabidiol at 5-HT1a receptors. Neurochem Res 30:1037-1043

297. Drysdale AJ, Ryan D, Pertwee RG, Platt B (2006) Cannabidiol-induced intracellular Ca2+ elevations in hippocampal cells. Neuropharmacology 50:621-631

298. Ryan D, Drysdale AJ, Lafourcade C, Pertwee RG, Platt B (2009) Cannabidiol targets mitochondria to regulate intracellular Ca2+ levels. J Neurosci 29: 2053-2063

299. Carrier EJ, Auchampach JA, Hillard CJ (2006) Inhibition of an equilibrative nucleoside transporter by cannabidiol: a mechanism of cannabinoid immunosuppression. Proc Natl Acad Sci U S A 103:7895-7900

300. O'Sullivan SE, Sun Y, Bennett AJ, Randall MD, Kendall DA (2009) Time-dependent vascular actions of cannabidiol in the rat aorta. Eur J Pharmacol 612:61-68

301. Takeda S, Usami N, Yamamoto I, Watanabe K (2009) Cannabidiol-2',6'dimethyl ether, a cannabidiol derivative, is a highly potent and selective 15lipoxygenase inhibitor. Drug Metab Dispos 37:1733-1737

302. Walter L, Franklin A, Witting A et al (2003) Nonpsychotropic cannabinoid receptors regulate microglial cell migration. J Neurosci 23:1398-1405

303. Rock EM, Kopstick RL, Limebeer CL, Parker LA (2013) Tetrahydrocannabinolic acid reduces nausea-induced conditioned gaping in rats and vomiting in Suncus murinus. Br J Pharmacol 170:641-648

304. Takeda S, Misawa K, Yamamoto I, Watanabe K (2008) Cannabidiolic acid as a selective cyclooxygenase-2 inhibitory component in cannabis. Drug Metab Dispos 36:1917-1921

305. Bolognini D, Rock EM, Cluny NL et al (2013) Cannabidiolic acid prevents vomiting in Suncus murinus and nausea-induced behaviour in rats by enhancing 5-HT1A receptor activation. Br J Pharmacol 168:1456-1470

306. Buchbauer G, Bohusch R (2015) Biological activities of essential oils: an update. In: Husnu Can Baser K, Buchbauer G (eds) Handbook of essential oils: science, technology, and applications, 2nd edn. CRC Press, Boca Raton, pp 281-322

307. Bowles EJ (2004) The chemistry of aromatherapeutic oils. Allen \& Unwin, Crows Nest

308. Paduch R, Kandefer-Szerszen M, Trytek M, Fiedurek J (2007) Terpenes: substances useful in human healthcare. Arch Immunol Ther Exp 55:315-327

309. Noma Y, Asakawa Y (2010) Biotransformation of monoterpenoids by microorganisms, insects, and mammals. In: Baser KHC, Buchbauer G (eds) Handbook of essential oils: science, technology, and applications. CRC Press, Boca Raton, pp 585-736

310. Rufino AT, Ribeiro M, Judas F et al (2014) Anti-inflammatory and chondroprotective activity of (+)-alpha-pinene: structural and enantiomeric selectivity. J Nat Prod 77:264-269

311. Neves A, Rosa S, Goncalves J et al (2010) Screening of five essential oils for identification of potential inhibitors of IL-1-induced Nf-kappaB activation and NO production in human chondrocytes: characterization of the inhibitory activity of alpha-pinene. Planta Med 76:303-308

312. Gil ML, Jimenez J, Ocete MA, Zarzuelo A, Cabo MM (1989) Comparative study of different essential oils of bupleurum gibraltaricum lamarck. Pharmazie 44:284-287

313. Him A, Ozbek H, Turel I, Oner AC (2008) Antinociceptive activity of a-pinene and fenchone. Pharmacol Online 3:363-369

314. Van Cleemput M, Cattoor K, De Bosscher K, Haegeman G, De Keukeleire D, Heyerick A (2009) Hop (Humulus lupulus)-derived bitter acids as multipotent bioactive compounds. J Nat Prod 72:1220-1230

315. Lorenzetti BB, Souza GE, Sarti SJ, Santos Filho D, Ferreira SH (1991) Myrcene mimics the peripheral analgesic activity of lemongrass tea. J Ethnopharmacol 34:43-48 
316. Rao VS, Menezes AM, Viana GS (1990) Effect of myrcene on nociception in mice. J Pharm Pharmacol 42:877-878

317. do Vale TG, Furtado EC, Santos JG Jr, Viana GS (2002) Central effects of citral, myrcene and limonene, constituents of essential oil chemotypes from lippia alba (Mill.) n.e. brown. Phytomedicine 9:709-714

318. Bisset NG, Wichtl M (2004) Herbal drugs and phytopharmaceuticals: a handbook for practice on a scientific basis, 3rd edn. Medpharm Scientific Publishers: Stuttgart; CRC Press, Boca Raton

319. Souza MC, Siani AC, Ramos MF, Menezes-de-Lima OJ, Henriques MG (2003) Evaluation of anti-inflammatory activity of essential oils from two Asteraceae species. Pharmazie 58:582-586

320. Rufino AT, Ribeiro M, Sousa C et al (2015) Evaluation of the antiinflammatory, anti-catabolic and pro-anabolic effects of E-caryophyllene, myrcene and limonene in a cell model of osteoarthritis. Eur J Pharmacol 750:141-150

321. Piccinelli AC, Santos JA, Konkiewitz EC et al (2015) Antihyperalgesic and antidepressive actions of (R)-(+)-limonene, alpha-phellandrene, and essential oil from Schinus terebinthifolius fruits in a neuropathic pain model. Nutr Neurosci 18:217-224

322. Hirota R, Roger NN, Nakamura H, Song HS, Sawamura M, Suganuma N (2010) Anti-inflammatory effects of limonene from yuzu (Citrus junos Tanaka) essential oil on eosinophils. J Food Sci 75:H87-H92

323. Chaudhary SC, Siddiqui MS, Athar M, Alam MS (2012) D-limonene modulates inflammation, oxidative stress and Ras-ERK pathway to inhibit murine skin tumorigenesis. Hum Exp Toxicol 31:798-811

324. d'Alessio PA, Ostan R, Bisson JF, Schulzke JD, Ursini MV, Bene MC (2013) Oral administration of d-limonene controls inflammation in rat colitis and displays anti-inflammatory properties as diet supplementation in humans. Life Sci 92:1151-1156

325. Kim MJ, Yang KW, Kim SS et al (2014) Chemical composition and antiinflammation activity of essential oils from citrus unshiu flower. Nat Prod Commun 9:727-730

326. Komori T, Fujiwara R, Tanida M, Nomura J, Yokoyama MM (1995) Effects of citrus fragrance on immune function and depressive states. Neuroimmunomodulation 2:174-180

327. de Almeida AA, Costa JP, de Carvalho RB, de Sousa DP, de Freitas RM (2012) Evaluation of acute toxicity of a natural compound (+)-limonene epoxide and its anxiolytic-like action. Brain Res 1448:56-62

328. Carvalho-Freitas Ml, Costa M (2002) Anxiolytic and sedative effects of extracts and essential oil from citrus aurantium L. Biol Pharm Bull 25:1629-1633

329. Pultrini Ade M, Galindo LA, Costa M (2006) Effects of the essential oil from citrus aurantium $L$. in experimental anxiety models in mice. Life Sci 78:1720-1725

330. Saiyudthong S, Marsden CA (2011) Acute effects of bergamot oil on anxiety-related behaviour and corticosterone level in rats. Phytother Res 25 : 858-862

331. Pimenta FC, Alves MF, Pimenta MB et al (2016) Anxiolytic effect of citrus aurantium L. on patients with chronic myeloid leukemia. Phytother Res 30 : 613-617

332. Komiya M, Takeuchi T, Harada E (2006) Lemon oil vapor causes an antistress effect via modulating the 5-HT and DA activities in mice. Behav Brain Res 172:240-249

333. Peana AT, D'Aquila PS, Chessa ML, Moretti MD, Serra G, Pippia P (2003) (-)-linalool produces antinociception in two experimental models of pain. Eur J Pharmacol 460:37-41

334. Peana AT, D'Aquila PS, Panin F, Serra G, Pippia P, Moretti MD (2002) Antiinflammatory activity of linalool and linalyl acetate constituents of essential oils. Phytomedicine 9:721-726

335. Peana AT, Marzocco S, Popolo A, Pinto A (2006) (-)-linalool inhibits in vitro NO formation: probable involvement in the antinociceptive activity of this monoterpene compound. Life Sci 78:719-723

336. de Sousa DP, Nobrega FF, Santos CC, de Almeida RN (2010) Anticonvulsant activity of the linalool enantiomers and racemate: investigation of chiral influence. Nat Prod Commun 5:1847-1851

337. Elisabetsky E, Marschner J, Souza DO (1995) Effects of linalool on glutamatergic system in the rat cerebral cortex. Neurochem Res 20:461-465

338. Ismail M (2006) Central properties and chemical composition of Ocimum basilicum essential oil. Pharm Biol 44:619-626

339. Silva Brum LF, Emanuelli T, Souza DO, Elisabetsky E (2001) Effects of linalool on glutamate release and uptake in mouse cortical synaptosomes. Neurochem Res 26:191-194
340. Nunes DS, Linck VM, da Silva AL, Figueiro M, Elisabetsky E (2010) Psychopharmacology of essential oils. In: Baser KHC, Buchbauer G (eds) Handbook of essential oils: science, technology, and applications. CRC Press, Boca Raton, pp 297-314

341. Nakamura A, Fujiwara S, Matsumoto I, Abe K (2009) Stress repression in restrained rats by (R)-(-)-linalool inhalation and gene expression profiling of their whole blood cells. J Agric Food Chem 57:5480-5485

342. Russo EB (2001) Handbook of psychotropic herbs: a scientific analysis of herbal remedies for psychiatric conditions. Haworth Press, Binghamton

343. Cline M, Taylor JE, Flores J, Bracken S, McCall S, Ceremuga TE (2008) Investigation of the anxiolytic effects of linalool, a lavender extract, in the male Sprague-Dawley rat. AANA J 76:47-52

344. Cheng BH, Sheen LY, Chang ST (2014) Evaluation of anxiolytic potency of essential oil and S-(+)-linalool from Cinnamomum osmophloeum ct. linalool leaves in mice. J Tradit Complement Med 5:27-34

345. Buchbauer G, Jirovetz L, Jager W, Dietrich H, Plank C (1991) Aromatherapy: evidence for sedative effects of the essential oil of lavender after inhalation. Z Naturforsch C 46:1067-1072

346. Jirovetz L, Buchbauer G, Jager W, Woidich A, Nikiforov A (1992) Analysis of fragrance compounds in blood samples of mice by gas chromatography, mass spectrometry, GC/FTIR and GC/AES after inhalation of sandalwood oil. Biomed Chromatogr 6:133-134

347. Buchbauer G, Jirovetz L, Jager W, Plank C, Dietrich H (1993) Fragrance compounds and essential oils with sedative effects upon inhalation. J Pharm Sci 82:660-664

348. Re L, Barocci S, Sonnino S et al (2000) Linalool modifies the nicotinic receptor-ion channel kinetics at the mouse neuromuscular junction. Pharmacol Res 42:177-182

349. Ghelardini C, Galeotti N, Salvatore G, Mazzanti G (1999) Local anaesthetic activity of the essential oil of lavandula angustifolia. Planta Med 65:700-703

350. Peana AT, Rubattu P, Piga GG et al (2006) Involvement of adenosine A1 and A2A receptors in (-)-linalool-induced antinociception. Life Sci 78:2471-2474

351. Batista PA, Werner MF, Oliveira EC et al (2008) Evidence for the involvement of ionotropic glutamatergic receptors on the antinociceptive effect of (-)-linalool in mice. Neurosci Lett 440:299-303

352. Kim JT, Ren CJ, Fielding GA et al (2007) Treatment with lavender aromatherapy in the post-anesthesia care unit reduces opioid requirements of morbidly obese patients undergoing laparoscopic adjustable gastric banding. Obes Surg 17:920-925

353. Klauke AL, Racz I, Pradier B et al (2014) The cannabinoid CB(2) receptorselective phytocannabinoid beta-caryophyllene exerts analgesic effects in mouse models of inflammatory and neuropathic pain. Eur Neuropsychopharmacol 24:608-620

354. Passos GF, Fernandes ES, da Cunha FM et al (2007) Anti-inflammatory and anti-allergic properties of the essential oil and active compounds from Cordia verbenacea. J Ethnopharmacol 110:323-333

355. Rogerio AP, Andrade EL, Leite DF, Figueiredo CP, Calixto JB (2009) Preventive and therapeutic anti-inflammatory properties of the sesquiterpene alpha-humulene in experimental airways allergic inflammation. Br J Pharmacol 158:1074-1087

356. Medeiros R, Passos GF, Vitor CE et al (2007) Effect of two active compounds obtained from the essential oil of cordia verbenacea on the acute inflammatory responses elicited by LPS in the rat paw. Br J Pharmacol 151: 618-627

357. Horvath B, Mukhopadhyay P, Kechrid M et al (2012) beta-caryophyllene ameliorates cisplatin-induced nephrotoxicity in a cannabinoid 2 receptordependent manner. Free Radic Biol Med 52:1325-1333

358. Ghelardini C, Galeotti N, Di Cesare Mannelli L, Mazzanti G, Bartolini A (2001) Local anaesthetic activity of beta-caryophyllene. Farmaco 56:387-389

359. Basile AC, Sertie JA, Freitas PC, Zanini AC (1988) Anti-inflammatory activity of oleoresin from Brazilian Copaifera. J Ethnopharmacol 22:101-109

360. Ozturk A, Ozbek H (2005) The anti-inflammatory activity of Eugenia caryophyllata essential oil: an animal model of anti-inflammatory activity. Eur J Gen Med 2:159-163

361. Apel MA, Lima ME, Sobral M et al (2010) Anti-inflammatory activity of essential oil from leaves of Myrciaria tenella and Calycorectes sellowianus. Pharm Biol 48:433-438

362. Al Mansouri S, Ojha S, Al Maamari E, Al Ameri M, Nurulain SM, Bahi A (2014) The cannabinoid receptor 2 agonist, beta-caryophyllene, reduced voluntary alcohol intake and attenuated ethanol-induced place preference and sensitivity in mice. Pharmacol Biochem Behav 124:260-268 
363. Gertsch J (2008) Anti-inflammatory cannabinoids in diet: towards a better understanding of $\mathrm{CB}(2)$ receptor action? Commun Integr Biol 1:26-28

364. Gertsch J, Leonti M, Raduner S et al (2008) Beta-caryophyllene is a dietary cannabinoid. Proc Natl Acad Sci U S A 105:9099-9104

365. Bahi A, Al Mansouri S, Al Memari E, Al Ameri M, Nurulain SM, Ojha S (2014) beta-caryophyllene, a CB2 receptor agonist produces multiple behavioral changes relevant to anxiety and depression in mice. Physiol Behav 135:119-124

366. Fernandes ES, Passos GF, Medeiros R et al (2007) Anti-inflammatory effects of compounds alpha-humulene and (-)-trans-caryophyllene isolated from the essential oil of Cordia verbenacea. Eur J Pharmacol 569:228-236

367. Chaves JS, Leal PC, Pianowisky L, Calixto JB (2008) Pharmacokinetics and tissue distribution of the sesquiterpene alpha-humulene in mice. Planta Med 74:1678-1683

368. Binet L, Binet $P$, Miocque M, Roux M, Bernier A (1972) Reserches sur les proprietes pharmcodynamiques (action sedative et action spasmolytique) de quelques alcools terpeniques aliphatiques. Ann Pharm Fr 30:611-616

369. Maurya AK, Singh M, Dubey V, Srivastava S, Luqman S, Bawankule DU (2014) Alpha-(-)-Bisabolol reduces pro-inflammatory cytokine production and ameliorates skin inflammation. Curr Pharm Biotechnol 15:173-181

370. Nurulain S, Prytkova T, Sultan AM et al (2015) Inhibitory actions of bisabolol on alpha7-nicotinic acetylcholine receptors. Neuroscience 306:91-99

371. Fischedick JT, Hazekamp A, Erkelens T, Choi YH, Verpoorte R (2010) Metabolic fingerprinting of cannabis sativa L., cannabinoids and terpenoids for chemotaxonomic and drug standardization purposes. Phytochemistry 71:2058-2073

372. Hillig KW (2004) A chemotaxonomic analysis of terpenoid variation in Cannabis. Biochem Syst Ecol 32:875-891

373. Hillig KW, Mahlberg PG (2004) A chemotaxonomic analysis of cannabinoid variation in cannabis (Cannabaceae). Am J Bot 91:966-975

374. Sawler J, Stout JM, Gardner KM et al (2015) The genetic structure of marijuana and hemp. PLoS One 10:e0133292

375. Lucas P, Walsh Z (2017) Medical cannabis access, use, and substitution for prescription opioids and other substances: a survey of authorized medical cannabis patients. Int J Drug Policy 42:30-35

376. Lucas P, Walsh Z, Crosby K et al (2016) Substituting cannabis for prescription drugs, alcohol and other substances among medical cannabis patients: the impact of contextual factors. Drug Alcohol Rev 35:326-333

377. Lucas P (2017) Rationale for cannabis-based interventions in the opioid overdose crisis. Harm Reduct J 14:58. https://doi.org/10.1186/s12954-017-0183-9

378. Nielsen S, Sabioni P, Trigo JM et al (2017) Opioid-sparing effect of cannabinoids: a systematic review and meta-analysis. Neuropsychopharmacology 42:1752-1765

379. Bushlin I, Rozenfeld R, Devi LA (2010) Cannabinoid-opioid interactions during neuropathic pain and analgesia. Curr Opin Pharmacol 10:80-86

380. Parolaro D, Rubino T, Vigano D, Massi P, Guidali C, Realini N (2010) Cellular mechanisms underlying the interaction between cannabinoid and opioid system. Curr Drug Targets 11:393-405

381. Welch SP, Stevens DL (1992) Antinociceptive activity of intrathecally administered cannabinoids alone, and in combination with morphine, in mice. J Pharmacol Exp Ther 262:10-18

382. Pugh G Jr, Smith PB, Dombrowski DS, Welch SP (1996) The role of endogenous opioids in enhancing the antinociception produced by the combination of delta 9-tetrahydrocannabinol and morphine in the spinal cord. J Pharmacol Exp Ther 279:608-616

383. Cichewicz DL, Welch SP, Smith FL (2005) Enhancement of transdermal fentanyl and buprenorphine antinociception by transdermal delta9tetrahydrocannabinol. Eur J Pharmacol 525:74-82

384. Cichewicz DL, Martin ZL, Smith FL, Welch SP (1999) Enhancement mu opioid antinociception by oral delta9-tetrahydrocannabinol: dose-response analysis and receptor identification. J Pharmacol Exp Ther 289:859-867

385. Collen M (2012) Prescribing cannabis for harm reduction. Harm Reduct J 9:1

386. Haroutounian S, Ratz Y, Ginosar $Y$ et al (2016) The effect of medicinal cannabis on pain and quality-of-life outcomes in chronic pain: a prospective open-label study. Clin J Pain 32:1036-1043

387. Boehnke KF, Litinas E, Clauw DJ (2016) Medical cannabis use is associated with decreased opiate medication use in a retrospective cross-sectional survey of patients with chronic pain. J Pain 17:739-744

388. Livingston MD, Barnett TE, Delcher C, Wagenaar AC (2017) Recreational cannabis legalization and opioid-related deaths in Colorado, 2000-2015. Am J Public Health 107:1827-1829
389. Scavone JL, Sterling RC, Weinstein SP, Van Bockstaele EJ (2013) Impact of cannabis use during stabilization on methadone maintenance treatment. Am J Addict 22:344-351

390. Raby WN, Carpenter KM, Rothenberg J et al (2009) Intermittent marijuana use is associated with improved retention in naltrexone treatment for opiate-dependence. Am J Addict 18:301-308

391. Bachhuber MA, Saloner B, Cunningham CO, Barry CL (2014) Medical cannabis laws and opioid analgesic overdose mortality in the United States, 1999-2010. JAMA Intern Med 174:1668-1673

\section{Submit your manuscript to a SpringerOpen ${ }^{\circ}$ journal and benefit from:}

- Convenient online submission

- Rigorous peer review

- Open access: articles freely available online

- High visibility within the field

Retaining the copyright to your article

Submit your next manuscript at $>$ springeropen.com 